\title{
VII. Von der Deutschen Akademie zum Goethe-Institut (1945-1960)
}

Mit einem vor allem wegen seiner Rolle beim „Anschluß“ Österreichs gesuchten Hauptkriegsverbrecher als Präsidenten, einem SS-Obergruppenführer als Leiter der wissenschaftlichen Abteilung und einer erst im Windschatten der Siege der Wehrmacht erfolgenden vollen Entfaltung ihrer Auslandsarbeit waren die Chancen der Deutschen Akademie nicht sehr hoch, den Zusammenbruch des Dritten Reiches zu überleben. Seit Anfang 1944 wurden vor allem auf britischer und amerikanischer Seite Überlegungen zur „Entnazifizierung“ Deutschlands und zur "Umerziehung" seiner Bewohner nach der Niederlage des NS-Regimes angestellt. ${ }^{1}$ Schon bei diesen ersten Planungen tauchte die Deutsche Akademie als eine Institution auf, die es im Zuge einer Entnazifizierung aufzulösen galt, und deren Personal von einer Weiterbeschäftigung im öffentlichen Dienst ausgeschlossen werden sollte. So sahen britische Überlegungen vom Mai 1944 für den Fall eines Waffenstillstandes eine Klausel zur Auflösung von NS-Organisationen vor: Unter der Kategorie I waren alle zentralen Parteieinrichtungen wie die Parteikanzlei, die Auslandsorganisation, das oberste Parteigericht, die Parteiamtliche Prüfungskommission, der Reichsorganisationsleiter, aber auch berufsständische NS-Einrichtungen wie die NS-Ärzteschaft und die Reichskulturkammer genannt. Diese insgesamt 43 Organisationen einschließlich aller regionalen und lokalen Gliederungen sollten sofort aufgelöst werden. Noch in der gleichen Rubrik hieß es am Ende: „There are a number of pseudo-scientific academies and institutions of a Nazi character. Many of those form part of a university and are covered by the directives on education. The following are independent, and their dissolution should therefore be provided for under this directive. "Das Dokument nannte sodann die Deutsche Akademie in München, das Institut zur Erforschung der Judenfrage in Frankfurt, das DAI in Stuttgart sowie die Staatsakademie für Rassenund Gesundheitspflege in Dresden. ${ }^{2}$ Eine Direktive für das Supreme Headquarters Allied Expeditionary Forces unter General Dwight D. Eisenhower vom 23. Februar 1945 zählte erneut die Deutsche Akademie, diesmal in Gesellschaft der Deutschen Jägerschaft, dem Reichsausschuß zum Schutz des Deutschen Blutes, der Reichskulturkammer, dem Institut zur Erforschung der Judenfrage, dem iberoamerikanischen Institut, dem Deutschen Fichte-Bund, dem DAI und der

1 Vgl. aus der Fülle der Literatur Clemens Vollnhals (Hrsg.), Entnazifizierung. Politische Säuberung und Rehabilitierung in den vier Besatzungszonen 1945-1949, München 1991; Günter Pakschies, Umerziehung in der britischen Zone 1945-1949, Weinheim 1979; Lutz Niethammer, Entnazifizierung in Bayern. Säuberung und Rehabilitierung unter amerikanischer Besatzung, Frankfurt/M. 1972 und James F. Tent, Mission on the Rhine. Reeducation and Denazification in American-Occupied Germany, Chicago u. a. 1982.

2 PRO FO 371/39141, War Cabinet Official Commitee on Armistice Terms and Civil Administration: Article 54 of the Draft British armistice with Germany, Mai 1944. 
Staatsakademie für Rassen- und Gesundheitspflege unter „other nazified organizations" auf, die zu verbieten waren und deren Personal von einer Wiederverwendung ausgeschlossen werden sollte. ${ }^{3}$ Die Akademie fiel offenbar auch unter die Kategorie jener „institutes and special bureaus devoting themselves to racial, political, militaristic or similiar research and propaganda", deren Schriftgut laut der berühmten Weisung JCS 1067 vom April 1945 für die in Deutschland zu etablierende US-Militärregierung von den einrückenden Truppen sicherzustellen sei. ${ }^{4}$ Denn als die Amerikaner im August 1945 in Schloß Höch bei Salzburg auf die Akten der Abteilung Auslandslektorate stießen, die sich in der Obhut von drei Lektoren befanden, beschlagnahmten sie diese und verschifften sie schließlich 1947 in die USA. Die Lektoren wurden verhaftet und über ihre Tätigkeit für die Akademie im Ausland befragt. ${ }^{5}$ Die seit Juli 1945 in der US-Zone ausgeteilten berühmten "Fragebögen“ zur Entnazifizierung, in denen jeder erwachsene Deutsche Auskunft über seine Aktivitäten während der NS-Zeit und Mitgliedschaften in angeblichen oder tatsächlich regimenahen Einrichtungen des Dritten Reichs zu geben hatte, führte denn auch die Deutsche Akademie explizit in Punkt 79 als eine von 54 namentlich genannten Organisationen auf.

Was genau die Alliierten bewog, die Deutsche Akademie auf diese Liste sofort aufzulösender NS-Institutionen zu setzten, ist nicht mehr feststellbar. Auch andere Institutionen hatten schließlich prominente Nationalsozialisten an ihrer Spitze, ohne daß sie automatisch dafür abgewickelt werden sollten. Zudem reichte die Geschichte der Akademie weit in die Weimarer Republik zurück, und bei ihrer Gründung waren Nationalsozialisten nicht beteiligt gewesen. Zwar hatte es, wie erwähnt, spätestens seit 1937 in der ausländischen Presse vereinzelte Artikel gegeben, welche die Akademie als NS-Propagandainstitution bezeichneten. Auf der anderen Seite war dies keineswegs der alleinige Eindruck, den die Akademie vor Kriegsausbruch bei ausländischen Beobachtern hinterließ. Der britische Konsul in München berichtete beispielsweise im Mai 1939 über die Deutsche Akademie in nüchternem, ganz auf die wissenschaftliche und auslandskulturpolitische Tätigkeit der Münchener Einrichtung abgestellten Ton, ${ }^{6}$ so daß sie dem Leser des Berichts wie das deutsche Pendant zum British Council, nicht aber wie eine parteipolitische Propagandainstitution erscheinen mußte. Die starke europaweite Präsenz der Akademie blieb bis Kriegsende im wesentlichen eine sprachpolitische, wenn auch vor allem in den letzten Kriegsjahren eine propagandistisch angehauchte. Ob sie sich jedoch dabei so sehr von den Aktivitäten beispielsweise des British Council in den Kriegsjahren unterschied, erscheint fraglich. Immerhin wurde zu keinem Zeitpunkt auf Ausländer Zwang ausgeübt, den Kursen der Akademie oder ihren sonstigen kulturpolitischen Aktivitäten beizuwohnen. Die Deutsche Akademie hatte auch nie irgendwelche exekutiven Befugnisse in den be-

3 PRO FO 371/46799, Retention in Office of Nazis and German Militarists, 23. 2. 1945.

4 Foreign Relations of the United States 1945. Bd. 3, S. 484-503, hier S. $488 \mathrm{f}$.

5 Helms Hardcastle, The Deutsche Akademic Munich, S. $569 \mathrm{ff}$.

6 PRO FO 371/23008, Bericht des britischen Konsuls über die Festversammlung der Deutschen Akademie mit beigefügtem Memorandum „Deutsche Akademie: Aims and Activities", 23. 5. 1939. 
setzten Ländern besessen. Gerechtfertigt mag die anvisierte Auflösung nicht so sehr aufgrund der konkreten Arbeit der Akademie selbst in den Kriegsjahren gewesen sein, sondern vor allem deswegen, weil sie wie alle öffentlichen und privaten Einrichtungen im Dritten Reich ein Instrument geworden war, das durch seine Weiterarbeit nach 1933 bzw. 1939 letztlich einem verbrecherischen Regime diente. Die Deutsche Akademie hatte dabei geholfen, dem Regime eine Fassade der angeblichen kulturellen Legitimation der Hegemonial- und Aggressionspolitik aufrechtzuerhalten.

Möglicherweise hat man aber auf alliierter Seite die Akademie mit einem geopolitischen "Think-Tank" Haushofers mit Ablegern in beinahe allen europäischen Staaten gleichgesetzt. ${ }^{7}$ Haushofer war seit Kriegsausbruch in der britischen wie amerikanischen Presse gelegentlich zu dem Mann hochstilisiert worden, der Hitler die Ideen für seine expansionistische Außen- und Kriegspolitik gegeben habe, am prominentesten sicherlich in einem Artikel des Londoner „Daily Express" vom Dezember 1939 unter der Überschrift "The Man behind Hitler's Ideas", in dem Haushofer im übrigen auch nach wie vor als Präsident der Akademie tituliert wurde. ${ }^{8}$ Dabei wurde im Kriege auch gelegentlich von einem großen "geopolitischen Institut" Haushofers in München mit mehreren hundert Mitarbeitern phantasiert, selbst innerhalb der britischen militärischen Aufklärung. ${ }^{9}$ Diese Überschätzung des Einflusses Haushofers und die fälschliche, holzschnittartige Gleichsetzung seiner außenpolitischen Ideen mit jenen Hitlers blieb zwar ab 1942 auf alliierter Seite nicht unwidersprochen. Sie zeitigte aber noch bei Kriegsende insoweit Nachwirkungen, als daß man auf amerikanischer Seite im Sommer 1945 überlegte, ob man Haushofer auf die Liste der Hauptkriegsverbrecher setzen solle. ${ }^{10}$ Auf alliierter Seite hielt sich auch der Glaube an die Existenz eines großen geopolitischen Instituts in München bis zum Kriegsende. So befragten amerikanische und britische Offiziere Haushofer über die Existenz und Aufgaben dieser angeblichen Einrichtung noch im Mai 1945.11 Es ist nicht ausgeschlossen, daß man auf westalliierter Seite der Deutschen Akademie Eigenschaften dieses vermeintlichen "geopolitischen Instituts“ zur Politikberatung der NSFührung und zur Informationsbeschaffung im und über das Ausland zugeschrieben hat.

Diese Fehlperzeption der Aufgaben und Tätigkeit der Akademie war unter den in München die kulturpolitische Regie übernehmenden US-Offizieren der für Schulen, Universitäten und Forschungseinrichtungen zuständigen „Education and Religious Affairs Section“ der Militärregierung offenbar verbreitet. Denn Thierfelder und Zwiedineck-Südenhorst glaubten in ihrer im August 1945 für die Amerikaner verfaßten Denkschrift „Die politische Tätigkeit der Deutschen Aka-

7 Norton, Karl Haushofer and the German Academy, S. $97 \mathrm{f}$.

8 Jacobsen, Haushofer, Bd. 1, S. $409 \mathrm{ff}$.

9 PRO WO 208/4467, Note on German Geopolitics, 9. 5. 1942. In dieser Aufzeichnung wird vor einer Überschätzung des Einflusses Haushofers auf die NS-Außenpolitik und Kriegführung gewarnt, zugleich hieß es: „We know little about the Geopolitical Institute at Munich. An aura of „Old Moore“ mystery is cultivated around this institute."

10 Jacobsen, Haushofer, Bd. 2, Dokument 301 (S. 568f.).

11 PRO FO 1078/34, Interrogation of Dr. Karl Haushofer, 4. und 16. 5. 1945. 
demie" dazu Stellung nehmen zu müssen. Das Dokument geht zwar mit der NSVergangenheit der Institution hart ins Gericht, nahm sie aber insoweit in Schutz, als „die Methoden der D. A. in diesen Jahren freilich nicht so gewesen [sind], wie das häufig in den nichtdeutschen Kreisen vermutet worden ist. Die D. A. war keine Spionage-Zentrale, die politische Agenten ins Ausland schickte, um dort unterirdisch gegen fremde Mächte zu konspirieren“. ${ }^{12}$

Auch wenn die Deutsche Akademie bei den Siegern auf der Liste der aufzulösenden Institutionen stand, bedeutete dies noch nicht definitiv ihr Ende. Vielmehr war im Frühjahr/Sommer 1945 ein gewisser Verhandlungsspielraum für ihr weiteres Schicksal gegeben; zum einen, weil sie naturgemäß nur eine untergeordnete Rolle in den Überlegungen der Amerikaner zur Entnazifizierung spielte; zum anderen, weil die Sieger sich wohl erst vor Ort ein tatsächliches Bild über den Grad der Verquickung der Akademie mit dem untergegangenen Regime machen wollten. Das Beispiel des DAI in Stuttgart, das seit 1944 ebenfalls auf der Liste der zu verbietenden wissenschaftlichen oder propagandistischen NS-Organisationen stand, tatsächlich aber nie von der Besatzungsmacht aufgelöst wurde, zeigt, daß eine bloße Erwähnung in den alliierten Planungen zur Entnazifizierung noch nicht automatisch das Ende bedeuten mußte. Zwar waren die Überlebenschancen der Akademie durch die prominenteren Nationalsozialisten an ihrer Spitze, die direkte Unterstellung unter das Propagandaministerium und die öffentlich sichtbare Auslandstätigkeit im Kriege schlechter als jene der Stuttgarter Einrichtung, die in den Kriegsjahren ein insgesamt unauffälligeres Dasein geführt hatte und der es gelang, sich den Amerikanern 1945/46 als rein wissenschaftliche Institution zu präsentieren. ${ }^{13}$ Allerdings gingen die im Krieg getätigten Studien des Stuttgarter Auslandsinstituts zur Rück- und Umsiedlung der auf dem Gebiet der UdSSR, in Südtirol und in Lateinamerika lebenden Deutschen ${ }^{14}$ Hand in Hand mit Überlegungen zur Entrechtung, Vertreibung oder gar Vernichtung der nichtdeutschen Bevölkerung vor allem auf dem Gebiet des besetzten Polens, die diesen Rückkehrern Platz zu machen hatte. Sie waren daher wesentlich enger mit den verbrecherischen Aspekten der NS-Politik verwoben als die zwar sichtbareren, aber letztlich harmloseren Sprach- und Propagandaaktivitäten der Deutschen Akademie, die sich auf das ohnehin als nicht "germanisierbar" angesehene Ausland beschränkten.

\section{Vergebliche Rettungsversuche}

Zunächst einmal begann unmittelbar, nachdem die Amerikaner München am 30. April 1945 besetzt hatten, ein Wettlauf um ihre Gunst von verschiedenen in München weilenden Personen, die der Akademie mehr oder weniger verbunden waren. Der erste, der bei den Amerikanern vorstellig wurde, war Mitte Mai 1945

12 BAB R51/8, Die politische Tätigkeit der Deutschen Akademie, Denkschrift Thierfelders und Zwiedineck-Südenhorsts vom 21. 8. 1945.

13 Ritter, Das Deutsche Auslandsinstitut in Stuttgart, S. 149.

14 Ebenda, S. $136 \mathrm{ff}$. 
Generalsekretär Schmitz. Er brachte gegenüber den US-Offizieren seine Zeit als Doktorand in Harvard und weitere Amerikaerfahrungen aus der Vorkriegszeit ins Spiel in der Hoffnung, die Akademie und damit sich selbst in die neue Zeit hinüber zu retten. Als Beamter des Propagandaministeriums war er naturgemäß nicht sonderlich geeignet, die neuen Herren in München von der Harmlosigkeit der Deutschen Akademie zu überzeugen. Aussichtsreicher als Mittler schien deshalb zunächst eine andere Gruppe innerhalb der Akademie. Während Seyß-Inquart die letzten Kriegstage in den Niederlanden und in Flensburg beim Hitler-Nachfolger Großadmiral Karl Dönitz verbrachte und andere Sorgen als das Schicksal der Deutschen Akademie hatte, übergab Vizepräsident Wüst in München die Amtsgeschäfte der Akademie mit Einmarsch der Amerikaner an Basler, den Leiter des Sprachamtes. Als Nichtparteigenosse, so Wüsts Hoffnung, würde dieser bessere Chancen haben, die Interessen der Deutschen Akademie gegenüber den Siegern zu vertreten. Basler wiederum zog zwei in München weilende und der Abteilung „Deutsche Sprache“ der Klasse „Wissenschaft und Forschung „ angehörende Ordinarien hinzu, die Germanisten Hans Heinrich Borcherdt, der u.a. in den USA gelehrt hatte, und Eduard Hartl. Dieses Triumvirat versuchte mit den Amerikanern Verhandlungen aufzunehmen und sich gleichzeitig eine gewisse Legitimation durch die Einberufung einer Versammlung der in und um München erreichbaren Mitglieder des Senats zu geben. ${ }^{15}$

Die drei Germanisten verfaßten Mitte Mai eine Denkschrift an die Militärregierung, in der sie für den Erhalt der Deutschen Akademie plädierten. Lediglich die praktische Abteilung, so der Grundtenor, habe seit 1933 den ursprünglichen $\mathrm{Ge}$ danken der Gründer der Akademie, eine streng wissenschaftliche und parteipolitisch neutrale Institution aufzubauen, durch Anlehnung an das Propagandaministerium pervertiert, „während die wissenschaftliche Abteilung in ihrer objektiven Grundhaltung und voraussetzungslosen Arbeitsweise im wesentlichen unangetastet blieb“. Es sei folglich bedauerlich, wenn wegen der politischen Belastung der praktischen Abteilung die großen und bedeutsamen Forschungsarbeiten der Deutschen Akademie abgebrochen werden müßten. Dies war natürlich in erster Linie ein Plädoyer für die Erhaltung der Abteilung Deutsche Sprache und des Sprachamtes, denn als bedeutende bisherige Forschungsleistungen der Akademie wurden in der Denkschrift lediglich Arbeiten aus diesem Bereich aufgeführt, so die bisher erschienenen zwei Bände der „Geschichte der deutschen Sprache“, das althochdeutsche Wörterbuch, sowie die im Kriege vom Sprachamt begonnene karteimäßige Erfassung der Gegenwartssprache durch Analyse der Presse. ${ }^{16}$ Die Amerikaner schienen zunächst gewillt, die Dreiergruppe als Sprachrohr der Deutschen Akademie anzuerkennen, denn am 25. Mai 1945 kam es zu einem Gespräch zwischen dem in der Education and Religious Affairs Section tätigen Hauptmann William Landeen und Borcherdt. Letzterer faßte die Unterredung so auf, als sei

15 BHStA MK 40446, Die Verhandlungen über die Deutsche Akademie, Aufzeichnung Borcherdts vom Sommer 1945.

16 Ebenda, Denkschrift über die Deutsche Akademie in München von Prof. Hartl, Prof. Borcherdt und Prof. Basler, ca. Mai 1945. 
ihm durch diese die Vertretung der Angelegenheiten der Deutschen Akademie zugesprochen worden. ${ }^{17}$

Parallel reklamierten jedoch mit Thierfelder und Zwiedineck-Südenhorst Anfang Juni auch zwei Akademie-Veteranen gegenüber dem neuen bayerischen Kultusminister Otto Hipp und seinem Staatsrat Hans Meinzolt, denen die Kontrolle über die vormaligen reichsunmittelbaren kulturellen Einrichtungen auf bayerischem Boden zugefallen war, für sich die Vertretung der Belange der Deutschen Akademie. Während Zwiedineck-Südenhorst nach seinem Ausscheiden aus der Akademie im Frühjahr 1937 weiterhin seinen Lehrstuhl für Volkswirtschaft und Staatswissenschaft an der Münchener Universität bekleidete, waren für Thierfelder die vorangegangenen acht Jahre schwieriger gewesen. ${ }^{18}$ Nach einem kurzen Zwischenspiel bei einem Berliner Verlag war er in den Jahren 1939 bis 1942, als er schließlich die Leitung der Volksbildungsstätte in München übernahm, freier Publizist. Dabei wurde er vom steten Mißtrauen der Partei verfolgt. ${ }^{19}$ Allerdings war er keineswegs persona non grata bei den Reichsbehörden, nicht einmal bei der Deutschen Akademie, wie Sieberts Überlegungen vom Frühjahr 1941 gezeigt hatten, ihn kommissarisch zum Generalsekretär zu berufen. Thierfelder galt auch nach 1937 als unbestrittene Autorität in Fragen der auswärtigen Kulturpolitik und der Sprachförderung, auf dessen Expertise das Regime ungern verzichten wollte. Vor allem im Auswärtigen Amt scheint man seine Dienste nach dem Ausscheiden aus der Akademie weiter geschätzt zu haben. Im Gegensatz zu seinen Selbststilisierungen nach Kriegsende - so behauptete er in dem Fragebogen der Amerikaner im Juli 1945, er sei auf Initiative von Heß von 1938 bis 1943 mit einem Verbot von Auslandsreisen belegt worden ${ }^{20}$ - bedeutete das Ausscheiden aus der Akademie keineswegs die pure materielle Not für ihn und seine Familie. Er schrieb beispielsweise im September 1940 an Senator Gerland:

„Meine Aufgabengebiete sind im Moment Konjunktur und ich kann mich kaum noch vor Arbeit retten. Nächste Woche halte ich vor SA-Führern in Magdeburg einen zweistündigen Vortrag über Indien. Am 28.10. habe ich eine Gastvorlesung über den Rundfunk als Mittel der zwischenstaatlichen Kulturwerbung an der Universität Freiburg [...] Zudem zeichnet sich eine neue Balkanfahrt, diesmal bezahlt, ab. Sie verfolgt ein Ziel, das die Eifersucht der Deutschen Akademie wecken könnte [...] Ich habe das und mehr verdient im letzten Jahr,

17 Ebenda, Die Verhandlungen über die Deutsche Akademie, Aufzeichnung Borcherdts vom Sommer 1945.

18 Vgl. Helms Hardcastle, Franz Thierfelder, S. $73 \mathrm{ff}$. Hardcastle übertreibt allerdings die "Märtyrerrolle" Thierfelders in den Jahren 1938-1945, indem sie unkritisch seinen Selbststilisierungen nach 1945 folgt, auf eine Analyse seiner damaligen Schriften und ihrer Auftraggeber hingegen gänzlich verzichtet.

$19 \mathrm{Vgl}$. die in Thierfelders Personalakte im Berlin Document Center des BAB befindlichen, mehrfachen Anfragen der Gauleitung der NSDAP (4. 11. 1938, 21. 11. 1942, 28. 1. 1943, 26. 6. 1944) bei der Ortsgruppe in Gräfelfing, dem Wohnort Thierfelders, bezüglich seiner politischen Einstellung und seines Verhaltens. Allerdings konnte die Ortsgruppe keinen Grund zur Beanstandung finden und berichtete lediglich, daß sich Thierfelder politisch vollkommen zurückhielt.

20 BAB R51/10116. Tatsächlich war er allein zwischen Herbst 1939 und Frühjahr 1940 mehrere Monate auf Balkanreise, wie aus der Korrespondenz mit Gerland hervorgeht, in: BAK N1010/38. Im Jahre 1942 war er sogar für die Deutsche Akademie in Bulgarien auf Vortragsreise. 
was mir die Deutsche Akademie zahlte, aber es war mühsam und aufregend, und krank darf ich einfach nicht werden. “21

Er verfaßte zwischen 1938 und 1943 allein 13 Monographien, von denen sieben dem Balkan gewidmet waren und u.a. der Verteidigung des deutschen Führungsanspruchs in diesem Großraum dienten. Unter den Monographien befanden sich, wie erwähnt, auch zwei gegen Großbritannien gerichtete Auftragsarbeiten für die Informationsabteilung des Auswärtigen Amts. Erst im Frühjahr 1943 wurde seine Situation im Dritten Reich anscheinend schwieriger, da er gut mit Professor Kurt Huber von der Münchener Universität befreundet gewesen war. Dessen Beteiligung an den Aktivitäten der "Weißen Rose" scheint das ohnehin vorhandene Mißtrauen der NSDAP gegen Thierfelder wesentlich verstärkt zu haben.22

In einer Denkschrift vom 18. Juni $1945^{23}$ zeichneten Zwiedineck-Südenhorst und Thierfelder jedenfalls ein etwas anderes Bild von der Akademie als das Dreigestirn Basler-Borcherdt-Hartl, von deren Bemühungen sie offenbar wußten. Der ehemalige Generalsekretär und der Ex-Vizepräsident stellten die Akademie als eine Organisation dar, die mitsamt der wissenschaftlichen Abteilung seit 1938 in den Dienst des Nationalsozialismus gestellt worden sei. Sie plädierten folglich für eine Umgestaltung der Deutschen Akademie, denn wegen der engen Anlehnung an den Nationalsozialismus wie auch wegen der nunmehr nicht mehr möglichen Auslandstätigkeit sei die überkommene Organisation obsolet geworden. Doch brauche eine Kulturnation wie die deutsche eine zentrale Institution, welche gegenüber dem eigenen Volk wie dem Ausland trotz aller materiellen Verelendung Zeugnis vom Willen zur Pflege der geistigen Werte ablege. Das Wirken der aus den Trümmern der Deutschen Akademie zu schaffenden neuen Organisation sollte laut Thierfelder und Südenhorst-Zwiedineck aber vornehmlich auf das deutsche Volk selbst abzielen, ganz im Sinne der von den Alliierten beabsichtigten Re-education der Deutschen. Die Deutschen müßten geläutert und geordnet in den Kreis der Kulturnationen zurückgeführt werden, indem man ihnen klarmache, daß Deutschland unauslösbarer Bestandteil des abendländischen Kulturkreises sei, der wiederum eine Schöpfung aller westlichen Nationen darstelle. Ferner müßten die Deutschen zum Umgang mit anderen Völkern erzogen werden, denn das mangelnde Verständnis für andere Völker habe die jetzige Katastrophe heraufbeschworen. Schließlich müsse die deutsche Sprache als derzeit einziges Binde-

21 BAK N1010/38, Brief Thierfelders an Gerland, 27. 9. 1940.

22 So die Tochter Thierfelders, Hannelore Wilke, in einem Leserbrief in der Süddeutschen Zeitung vom 11. 10.1991, in dem sie ihren Vater als engagierten Gegner der NS-Regimes bezeichnete. Der Brief war eine Antwort auf einen Artikel vom 10./11. 8. 1991 in der Süddeutschen Zeitung von Bernhard Witteck, in dem der Gründung des Goethe-Instituts 40 Jahre zuvor unter der Überschrift „Große Vision eines kleinen Mitläufers" gedacht worden war. Allerdings kann, wie in dem Leserbrief behauptet, von einem „Untertauchen “ als Folge der Kontakte zu Huber und der Gefahr der Verhaftung schwerlich die Rede sein. Denn wenn die NSDAP-Kreisleitung noch im Juni 1944 aufgefordert wurde, über Thierfelders politische Haltung zu berichten und nichts Neues gegenüber den vorangegangenen Einstellungen und Verhaltensweisen des Beobachtungsobjektes melden konnte, darf wohl eher von einer unauffälligen als von einer Untergrundexistenz Thierfelders gesprochen werden.

${ }^{23}$ BHStA MK 40446, Denkschrift über die Deutsche Akademie, 18. 6. 1945. 
glied der Deutschen in ihrer Gestalt und ihrem Wesen erforscht und erhalten werden. Dies war ein Vorschlag, der möglicherweise als Konzession an die Bestrebungen der Gruppe um Borcherdt gedacht war, um diese für eine Umgestaltung zu gewinnen. Die an die Stelle der Deutschen Akademie tretende Einrichtung solle den Namen „Institut für Kulturforschung und Volkskunde“ tragen. In Anlehnung an die Vorgängerinstitution sollte sie eine wissenschaftliche Abteilung besitzen, die Forschungen auf dem Gebiet der Kulturgeschichte, der Völkerpsychologie, der Linguistik und Auslandskunde betreiben, und eine praktische Abteilung, die sich um die Vermittlung ihrer Erkenntnisse in der deutschen Öffentlichkeit bemühen würde. Sollte hingegen die Besatzungsmacht sich dafür entscheiden, eine Neugründung aus den Resten der Deutschen Akademie abzulehnen, so hielten die Autoren der Denkschrift es für die beste Lösung, die wissenschaftlichen Arbeiten der Deutschen Akademie von der Bayerischen Akademie der Wissenschaften fortführen zu lassen und das Vermögen und den Sachbesitz der Deutschen Akademie der Stadt München und dem Land Bayern zu übertragen.

Die Gruppe um Borcherdt wiederum wußte seit Mitte Juni, daß Thierfelder und Zwiedineck-Südenhorst eine neue Einrichtung ansteuerten, sprachen ihnen aber das Recht zu einem solchen Schritt ab unter dem Hinweis, hierzu müßten die über ganz Deutschland verstreuten Mitglieder der wissenschaftlichen Abteilung der Deutschen Akademie zuvor gehört werden. Eine Auflösung mit anschließender Neugründung hielt Borcherdt angesichts der wirtschaftlichen Verhältnisse für unverantwortlich, ebenso eine Vertretung der Interessen der Deutschen Akademie durch den "Nichtwissenschaftler" Thierfelder. ${ }^{24}$ Allerdings standen die Chancen der Gruppe um Borcherdt schlecht, sich gegen den Führungsanspruch des ehemaligen Generalsekretärs und des ehemaligen Vizepräsidenten in Fragen der zukünftigen Gestaltung der Akademie durchzusetzen. Dies vor allem, weil beide als Nichtparteimitglieder durch ihr Ausscheiden aus der Akademie im Jahre 1937, das sie natürlich mit ihren hartnäckigem, aber letztlich vergeblichen Widerstand gegen die Nazifizierung der Akademie begründeten, eine politisch einigermaßen saubere Weste vorzuweisen versuchten, ja fast als Widerstandskämpfer erschienen. „Der Grund des Ausscheidens für Dr. Thierfelder war die Wahrnehmung, daß die Deutsche Akademie ab 1937 in rein politischem Fahrwasser segelte, und sich dadurch von ihren ursprünglichen Zielen entfernte", hieß es entsprechend im Protokoll einer Unterredung, die Thierfelder am 22. Juni 1945 mit Staatsrat Meinzolt über die Zukunft der Deutschen Akademie hatte. 25 Thierfelder konnte sich in diesem Gespräch als kompetenter und verantwortungsbewußter Vertreter der Interessen der Akademie durch eine Reihe weiterer Vorschläge empfehlen: Er bezeichnete als vordringliche Aufgabe den Abbau des in den letzten Kriegsjahren aufgeblähten personellen Apparates der Akademie. Dies war ein für den bayerischen Staat sinnvoller Vorschlag, da dieser unmöglich die Summen aufbringen konnte, die in den Kriegsjahren aus den Kassen des Reiches in die Akademie geflossen waren. Sodann wies Thierfelder auf die Notwendigkeit der Betreu-

24 Ebenda, Schreiben Borcherdts an den bayerischen Staatsminister für Unterricht und Kultus, 16. 6. 1945.

25 Ebenda, Protokoll des Gesprächs zwischen Meinzolt und Thierfelder vom 22.6. 1945. 
ung der im „Rückwandererheim“ in Untergrainau versammelten, aus dem Ausland zurückgekehrten Lektoren und Lektorinnen und ihrer Familien hin. ${ }^{26}$ Schließlich glaubte er durch die zukünftige Ausrichtung der Akademie auf die Erforschung der abendländischen Kultur und die Umerziehung der Deutschen auch die Besatzungsmacht für eine Ersatzinstitution an Stelle der Deutschen Akademie gewinnen zu können. Ihren Namen hielt er im übrigen für im Ausland zu belastet, um ihn weiter zu benutzen. Letztlich fehlte auch nicht der Hinweis, daß Borcherdt niemals eine führende Rolle in der Akademie innegehabt habe, wohingegen Thierfelders Verbündeter Zwiedineck-Südenhorst angeblich der letzte rechtmäBige Präsident der Deutschen Akademie gewesen sei. „Dr. Thierfelder macht mir persönlich sowohl nach der sachverständigen, wie auch nach der charakterlichen Seite hin einen ausgezeichneten Eindruck “, resümierte Meinzolt das Gespräch. ${ }^{27}$ Vier Tage später ernannte das Kultusministerium Zwiedineck-Südenhorst zum kommissarischen Präsidenten und Thierfelder zum kommissarischen Generalsekretär der Deutschen Akademie. Am folgenden Tag informierte Kultusminister Hipp die Militärregierung. Er bat nicht nur um deren Zustimmung zur personalpolitischen Entscheidung, sondern auch um die Freigabe von $100000 \mathrm{RM}$ aus dem von der Besatzungsmacht gesperrten Guthaben der Akademie, damit die Rückführung der durch die Kriegsfolgen über Bayern und das Salzburger Land verstreuten Besitztümer der Akademie und gegebenenfalls ihre Abwicklung beginnen könne. ${ }^{28}$

Eine endgültige Entscheidung über Abwicklung oder Weiterführung der Akademie mit veränderter Aufgabenstellung und neuem Namen war mit der Ernennung Thierfelders und $Z$ wiedineck-Südenhorsts also noch nicht gefallen. Die kommissarischen Leiter mußten aber bald erkennen, daß es schwer sein würde, die Besatzungsmacht davon zu überzeugen, die Deutsche Akademie selbst in einer veränderten Struktur und Aufgabenstellung zu erhalten. Zu tief saß anscheinend auf amerikanischer Seite das Mißtrauen gegen diese. Denn Ende Juli schlug Zwiedineck-Südenhorst dem bayerischen Kultusministerium plötzlich vor, aus der Konkursmasse der Deutschen Akademie nicht mehr ein „Institut für Kulturforschung und Volkskunde" zu schaffen, sondern ein "Institut zur Erforschung des Nationalsozialismus" zu errichten, welches das Schrifttum des Nationalsozialismus sammeln und auswerten sollte. ${ }^{29}$ Die Aufgabe der Nachfolgeorganisation sollte offenbar stärker eingegrenzt, klarer wissenschaftlich ausgerichtet und noch besser in ein mögliches Re-educationprogramm der Besatzungsmacht einfügt werden, um das Mißtrauen der Militärregierung zu zerstreuen. Das Ministerium

26 Mitte Juli 1945 lebten hier 40 Lektoren, der Verbleib von 52 weiteren noch im Ausland weilenden Lektoren war zu diesem Zeitpunkt ungewiß. In: Ebenda, Haushaltsvoranschlag für die Abwicklung der Deutschen Akademie, Aufzeichnung Thierfelders vom 14. 7. 1945.

27 Ebenda, Protokoll des Gesprächs Meinzolt und Thierfelder vom 22. 6. 1945.

28 BAB R51/9, Schreiben Hipps an die Militärregierung in München, 27. 6. 1945.

29 BHStA MK 40446, Schreiben Zwiedineck-Südenhorsts an das bayerische Kultusministerium, 25. 7. 1945. 
unterstützte diesen Vorschlag gegenüber den Amerikanern unter Hinweis auf die politische Unbelastetheit Zwiedineck-Südenhorsts und Thierfelders. ${ }^{30}$

Am 6. August 1945 hatten die beiden eine Unterredung mit dem Leiter der Education and Religious Affairs Section, Major Edward F. d'Arms. Dieser gab ihnen allerdings zu verstehen, daß die Besatzungsmacht nicht am Weiterbestehen der Deutschen Akademie interessiert sei, auch nicht in der veränderten Form eines Instituts zur Erforschung des Nationalsozialismus. Die Abneigung der Amerikaner gegen die Deutsche Akademie oder eine wie auch immer geartete Nachfolgeorganisation gründete sich darauf, daß sie diese nach wie vor als eine Institution ansahen, die vornehmlich im Ausland Spionage betrieben habe. ${ }^{31}$ Major d'Arms forderte die beiden dennoch nach der Unterredung auf, eine Denkschrift über die politische Vergangenheit der Deutschen Akademie und einen Bericht über den Stand der wissenschaftlichen Arbeit zu verfassen, ${ }^{32}$ was offenbar bei den Adressaten als Chance begriffen wurde, doch noch aus den Resten der Akademie etwas Neues gründen zu können. So hatte Zwiedineck-Südenhorst den Eindruck, daß man die Amerikaner gewinnen könne, wenn man sich nur klar genug vom Namen der Deutschen Akademie und ihrer Tätigkeit bis 1945 distanziere und etwas konkretes Neues an ihre Stelle setze. Thierfelder ventilierte daraufhin die Idee einer "GoetheAkademie für wissenschaftliche Kulturbesinnung und geistige Zusammenarbeit", die in ihrer Aufgabenstellung ganz eng an den Vorschlag für ein „Institut für Kulturforschung und Volkskunde" vom Juni 1945 angelehnt war. ${ }^{33}$

Thierfelder entließ derweil die Angestellten und Lektoren der Akademie stufenweise ab dem 30. Juni. Zugleich kümmerte er sich um die Erfassung des verstreuten Besitzes und seine Rückführung nach München. Parallel machten die kommissarischen Leiter sich, wie von der Besatzungsmacht gewünscht, Mitte August an die Aufarbeitung der politischen Vergangenheit der Akademie, zumindest so, wie sie ihnen für ihre weiteren Pläne opportun erschien. Dies geschah in Form einer Denkschrift, die mit „Die politische Aktivität der Deutschen Akademie“ betitelt war und die, auf Englisch wie Deutsch verfaßt, vom 21. August 1945 datierte. ${ }^{34}$ Tenor dieser Denkschrift war die Behauptung, daß die Akademie ursprünglich und bis in das Jahr 1937 hinein ein rein kulturelles, überparteiliches, von staatlicher Einflußnahme freies, demokratisch verfaßtes und auch unter ausländischen Gelehrten anerkanntes Unternehmen gewesen sei, das sich zudem jeder Einmischung in ausländische Angelegenheiten enthalten habe. Folglich, so die Autoren, galt die Deutsche Akademie bei der Machtübernahme der Nationalsozialisten „als eine unzeitgemäße, politisch unzuverlässige Organisation des Weimarer Systems, die der Umgestaltung bedurfte oder beseitigt werden müßte“. Die Akademie sei dann ab 1933 schleichend - vor allem unter dem unheilvollen Einfluß Haushofers und gegen den Widerstand der Verfasser - im NS-Sinne pervertiert worden. Mit dem Weggang Thierfelders und Zwiedineck-Südenhorsts im

30 Ebenda, Schreiben des Kultusministeriums an die Militärregierung, 28. 7. 1945.

31 Harvolk, Eichenlaub und Hakenkreuz, S. 48.

32 BHStA MK 40446, Schreiben Thierfelders an Meinzolt, 16. 8. 1945.

33 Harvolk, Eichenlaub und Hakenkreuz, S. $48 \mathrm{f}$.

34 Deutsches und englisches Original in: BAB R51/8. 
Jahre 1937 seien schließlich alle Schranken des Anstandes gefallen. Verschwendung öffentlicher Gelder und Bestechung habe Einzug gehalten, die demokratische Verfassung sei endgültig dem Führerprinzip gewichen, charakterlich unzulängliche und fachlich nicht qualifizierte Parteigenossen hätten alle führenden Positionen besetzt und die Deutsche Akademie in eine politische Propagandainstitution verwandelt, was einem „Verrat an den Grundsätzen der freien wissenschaftlichen Forschung“ und dem „Mißbrauch kultureller Wirksamkeit zu außenpolitischen Zwecken" gleichgekommen sei. Der politischen Vereinnahmung hätten sich schließlich auch die Auslandslektorate nicht entziehen können. Sie hätten im Krieg auf Geheiß der Zentrale politische Propaganda betreiben müssen, obwohl die große Mehrheit der Lektoren einwandfreie Persönlichkeiten gewesen seien. In ihrer Mehrzahl habe sie der ehrliche Willen beseelt, den fremden Schülern „deutsche Wesensart" beizubringen, und ihr Gastland sei ihnen meist zur zweiten Heimat geworden. Viele hätten geradezu physisch darunter gelitten, ihre Tätigkeit der Kulturwerbung mit Propagandaaufgaben koppeln zu müssen. Die angeblich für die Politisierung der Akademie Verantwortlichen wurden in dunkelsten Tönen geschildert, allein schon, um sie dauerhaft von einem Mitspracherecht in den Geschicken der Akademie oder jeglicher Nachfolgeorganisation auszuschließen: Haushofer war angeblich wissenschaftlich bedeutungslos, krankhaft geltungsbedürftig und vermutlich homosexuell; sein Zögling Fochler-Hauke, der die konsequente Nazifizierung der Geschäftsstelle und der wissenschaftlichen Abteilung zu verantworten habe, wurde als begabt, aber skrupellos und ehrgeizig hingestellt, Kölbl als unbedeutend und kriminell, von der Leyen als schwach und charakterlos. Wüst machte in der Darstellung der beiden Verfasser seinem Namen alle Ehre, indem sie ihn als von maßlosem Ehrgeiz beseelt, von Minderwertigkeitskomplexen erfüllt, gewissenlos und hemmungslos auf den eigenen Vorteil bedacht schilderten. Schmitz schließlich habe seine Tätigkeit als Generalsekretär zur persönlichen Bereicherung genutzt. Die Autoren sahen die Hauptschuld der Deutschen Akademie darin, daß sie den Vereinnahmungsversuchen von Staat und Partei nicht mehr Widerstand entgegengesetzt habe. Sie empfahlen ferner eine genaue Überprüfung des Personals der Geschäftsstelle und der Lektoren, unter denen es auch vereinzelte schwarze Schafe gegeben habe. Die Autoren gaben sich aber überzeugt, daß „die Deutsche Akademie nach ihrer Reinigung die Arbeit im Geiste von einst wieder aufnehmen könnte".

Thierfelder und Zwiedineck-Südenhorst schossen jedoch über ihr Ziel hinaus, durch klare Distanzierung von der Vergangenheit der Deutschen Akademie aus ihren Überresten eine irgendwie geartete zentrale deutsche kulturelle Nachfolgeinstitution erstehen zu lassen. Vermutlich erzeugten sie trotz des Hinweises auf die ursprünglich guten Wurzeln der Deutschen Akademie bei den Adressaten in der Militärregierung eine eher gegenteilige Wirkung, fiel doch die Bilanz der vergangenen acht Jahre in der Schilderung Thierfelders und Zwiedineck-Südenhorsts, die wohl auch von persönlichen Rachegefühlen mitgeprägt war, vor allem wegen der vollständigen Diskreditierung des nach 1937 führenden Personals derartig düster aus. Zugleich klangen ihre mehrfach geänderten Vorschläge für eine Nachfolgeorganisation nicht sehr überzeugend, sondern zeugten eher von einer opportunistischen Anpassungsfähigkeit der Autoren, gespeist aus dem Wunsch, 
die Hinterlassenschaft der Akademie, immerhin ein Barvermögen von fast 1,6 Millionen RM, ${ }^{35}$ zum eigenen Vorteil zu nutzen. Daß dies sicherlich eines der Motive war, das vor allem Thierfelder antrieb, für den Erhalt der Deutschen Akademie bzw. die Umformung in eine veränderte Nachfolgeorganisation zu kämpfen, wird u. a. an einer Aufstellung Thierfelders vom Juli 1945 über Entschädigungen für ehemalige Angehörige der Deutschen Akademie deutlich. Hier führte er Mitarbeiter der Akademie auf, die aufgrund politischer oder rassischer Gründe entlassen und folglich nicht in den Genuß fristgerechter Kündigungstermine oder der gesetzlich vorgesehenen Weiterzahlung der Bezüge gekommen waren. Neben drei Personen, die 150, 1736 und 2210 RM für rechtswidrige Entlassungen wegen jüdischer Abstammung, defaitistischer Äußerungen und verschwiegener politischer Betätigung erhalten sollten, forderte Thierfelder für sich selbst eine Nachzahlung von 13500 RM für entgangene Versicherungszuschüsse der Deutschen Akademie unter dem Hinweis, er sei aus politischen Gründen entlassen worden. Dabei verschwieg er allerdings, daß er im Oktober 1936 selbst gekündigt hatte, die $\mathrm{Zu}$ schüsse allerdings laut Arbeitsvertrag nur für den Fall einer Kündigung durch die Akademie fortgezahlt werden sollten. ${ }^{36}$ Außerdem hatte er in Absprache mit dem Schatzmeister Kisskalt im Jahre 1938 eine einmalige Abschlagsumme erhalten und dafür auf seine Versicherungszuschüsse verzichtet.

Anfang September 1945 wurde Thierfelder von der Militärregierung mitgeteilt, $\mathrm{daß}$ die Deutsche Akademie voraussichtlich aufgelöst werde. ${ }^{37}$ Dabei mag die Militärregierung in ihrem Entschluß, nun, nach einigen Monaten der Überlegung der Deutschen Akademie tatsächlich den Garaus zu machen, durch den im Spätsommer aufkommenden sogenannten Bavarian Scandal bestärkt worden sein. Eine Reihe von Artikeln in der US-Presse über die zu laxe Entnazifizierungspraxis in Bayern hatte im Sommer 1945 die Militärregierung in Bayern unter Druck geraten lassen. Sie wurde von Eisenhower aufgefordert, zukünftig strengere Maßstäbe bei der Begutachtung von zu verwendendem deutschen Personal anzulegen. Sichtbarste Folge dieser Kritik war die Entlassung des ersten bayerischen Ministerpräsidenten Fritz Schäffer Ende September 1945, dessen Entnazifizierungspraxis als zu "lau“ angesehen wurde. ${ }^{38}$ In dieser Situation, als aus Washington wie Heidelberg härteres Vorgehen gefordert wurde, erschien die Auflösung der ohnehin verdächtigen Akademie aus Sicht der Education and Religious Affairs Section das Gebot der Stunde.

Die erhaltenen Akten ${ }^{39}$ vermitteln nicht den Eindruck, als hätten Thierfelder

35 Der Vermögensstand der Deutschen Akademie zum 1. 8. 1945 wurde mit 1,567 Millionen RM beziffert, davon 1,060 Millionen RM des Wirtschaftsrates, 207000 RM Barschaft in der Kasse, 175000 RM Stiftungsvermögen und 124000 RM als Spezialfonds des Präsidenten, in: BAB R51/8.

36 BHStA MK 40446, Aufstellung von Fällen der Wiedergutmachung für Angestellte, die aus politischen oder rassischen Gesichtspunkten entlassen wurden, Juli 1945.

37 Ebenda, Schreiben des Kultusministeriums an die Militärregierung, 8. 9. 1945.

38 Niethammer, Entnazifizierung in Bayern, S. $232 \mathrm{ff}$.

39 Neben dem Band BHStA MK 40446 gibt es zwei Aktenbände zur Abwicklung der Deutschen Akademie im Archiv der Bayerischen Akademie der Wissenschaften (AdBAdW) in München. 
und Zwiedineck-Südenhorst nach diesem Zeitpunkt noch verzweifelt um den Aufbau einer Nachfolgeorganisation aus den Trümmern der Deutschen Akademie gekämpft. Dies mag auch daran gelegen haben, daß sich der kommissarische Generalsekretär und der kommissarische Präsident irgendwann im Herbst 1945 entzweiten. ${ }^{40} \mathrm{Am}$ 14. Dezember bat Zwiedineck-Südenhorst das Kultusministerium, bei der Militärregierung zum Jahresende die Auflösung der Akademie zu beantragen und ihn vom Amt des Präsidenten zu entbinden. ${ }^{41}$ Thierfelder hatte parallel zu seiner Tätigkeit als kommissarischer Generalsekretär der Deutschen Akademie am 20. Oktober 1945 das Amt des Syndikus der Münchener Universität und der Bayerischen Akademie der Wissenschaften übernommen, ${ }^{42}$ so daß er zumindest in materieller Hinsicht nicht mehr auf ein Weiterbestehen der Deutschen Akademie zu dringen brauchte. Am 26. Dezember ordnete die Militärregierung schließlich an, daß die Akademie zum 31. Dezember die Tätigkeit einzustellen habe und alle Angestellten zu entlassen seien.

Das restliche Vermögen von 1,463 Millionen RM wurde von der Militärregierung eingezogen und im Jahre 1948 dem Bayerischen Landesvermögensamt übergeben. Die Bayerische Akademie der Wissenschaften erbte das Haus in der MariaJosepha-Straße, in dem sich das Goethe-Institut seit 1941 befunden hatte. Mobiliar, Bücher und technische Geräte gingen ebenfalls zum Teil an sie, zum Teil an die Bayerische Staatsbibliothek und diverse Bildungseinrichtungen der Stadt München. Die Bayerische Akademie der Wissenschaften führte einen Teil der Forschungen der Deutschen Akademie weiter, vor allem die Sprachforschung, die Ortsnamensforschung und die seit den zwanziger Jahren zusammen mit der Deutschen Akademie betriebene Arbeit an der Neuen Deutschen Biographie. Durch die Fortführung der wissenschaftlichen Arbeit der aufgelösten Organisation erhoffte sie, eines Tages auch das finanzielle Erbe der Deutschen Akademie antreten zu können. ${ }^{43}$ Dieses entsprach immerhin etwa dem Siebenfachen des Jahresbudgets der Bayerischen Akademie der Wissenschaften im Jahre 1946/47.

Ein kleiner Abwicklungsstab ohne Thierfelder, der sein Amt ebenfalls am 31. Dezember 1945 niederlegte, arbeitete noch bis Frühjahr 1947 an der Rückführung der Besitztümer der aufgelösten Einrichtung nach München, ihrem Verkauf oder der Übertragung an geeignete Erben, der Begleichung noch ausstehender Rechnungen und der Ausstellung von Dienstzeugnissen und sonstigen Nachweisen für das ehemalige Personal der Deutschen Akademie. Das Kapitel Deutsche Akademie schien endgültig abgeschlossen zu sein. Abgesehen von den Zeitumständen, die vorerst ohnehin nicht an eine Wiederauflage zentral gesteuerter deut-

40 So Zwiedineck-Südenhorst 1951, in: AdBAW Deutsche Akademie Bd. 2, Protokoll über die Besprechung betreffend die ehemalige Deutsche Akademie, 22. 3. 1951.

41 BHStA MK 40446, Schreiben Zwiedineck-Südenhorsts an das Kultusministerium, 14. 12. 1945. Am selben Tag schrieb Thierfelder an einen Bekannten, die Entscheidung über die Schlußliquidation der Deutschen Akademie sei immer noch nicht getroffen, aber sie stehe unmittelbar bevor, in: AdBAdW Deutsche Akademie Bd. 2, Thierfelder an Prof. Anton Kippenberg, 14. 12. 1945.

42 Helms Hardcastle, Franz Thierfelder, S. 91.

43 AdBAdW Deutsche Akademie Bd. 1, Schreiben des Präsidenten der Bayerischen Akademie der Wissenschaften an das bayerische Kultusministerium, 29. 9. 1949. 
scher Kulturwerbung im Ausland denken ließen, gab es mit der Bayerischen Akademie der Wissenschaften auch eine deutsche Institution, die allein schon aus finanziellen Gründen kein Interesse an einem Wiederaufleben der Deutschen Akademie hatte und folglich nicht müde wurde, auf die unselige politische Vergangenheit der ehemaligen Körperschaft des Öffentlichen Rechts hinzuweisen.

\section{Der Wiesbadener Arbeitskreis}

Ende 1948 setzte bei Thierfelder eine Rückbesinnung auf die Deutsche Akademie ein, die den Zeit- wie persönlichen Umständen geschuldet war. Im Januar 1948 hatte er dem Leiter des deutschen Volksliedarchivs in Freiburg, dem Volkskundler und ehemaligen Mitglied der wissenschaftlichen Abteilung der Deutschen Akademie, John Meier, noch mitgeteilt, daß bei der Liquidation der Deutschen Akademie etwa 1,4 Millionen RM übriggeblieben seien, die der bayerische Staat verwalte. Meier solle versuchen, einen Teil des Geldes für das Volksliedarchiv zu erhalten. ${ }^{44}$ Diese Äußerung ist ein Indiz dafür, daß Thierfelder zu diesem Zeitpunkt noch nicht an die Wiedererstehung der Deutschen Akademie dachte, sondern an eine möglichst sinnvolle Verwendung ihres Geldes zur Dokumentation des deutschen kulturellen Erbes. Ende November 1948 hingegen versandte Thierfelder ein Rundschreiben "An die Mitglieder der ehemaligen Deutschen Akademie“, das an 13 ehemalige Senatoren, 13 Mitglieder der wissenschaftlichen Abteilung, sieben der praktischen Abteilung und sieben aus dem Kreis der Freunde der Akademie ging. Unter den Adressaten befanden sich unter anderem Konrad Adenauer, Rudolf Pechel, Christian Eckert und Kurt Magnus als ehemalige Senatoren der Akademie sowie Zwiedineck-Südenhorst, Meier und Fehn. Durch den sich verschärfenden Kalten Krieg zeichnete sich zu diesem Zeitpunkt die Gründung eines westdeutschen Teilstaats ab. Spätestens mit der Aufnahme der Arbeit des Parlamentarischen Rats ab September 1948 in Bonn wurde dies auch der deutschen Öffentlichkeit deutlich. Diese Entwicklung hat vermutlich zu Thierfelders Gesinnungswandel in bezug auf die Deutsche Akademie geführt. Anders als noch zu Beginn des Jahres 1948 erschienen im Herbst 1948 die Chancen, im Zuge der Entstehung eines deutschen Teilstaates auch eine zentrale deutsche kulturpolitische Organisation aus der Taufe heben zu können, nun wesentlich aussichtsreicher, aber auch die Gefahr einer Spaltung der Nation wurde immer realer. Thierfelder ventilierte in seinem Schreiben folglich die Idee einer neuen, der Deutschen Akademie geistesverwandten, gesamtdeutschen Kulturorganisation, deren Gründung nun noch dringender als nach dem Ersten Weltkrieg sei: Damals habe lediglich die Existenz der zerrütteten Nation auf dem Spiel gestanden, ,heute steht nicht mehr nur unsere nationale Existenz, sondern das gesamte Dasein der abendländischen Kultur in Frage" ${ }^{45}$ Zugleich sollte die neue Organisation, die er nicht als Rechtsnachfolgerin der Deutschen Akademie sah, aber als sinnvolle Fortentwicklung

${ }^{44}$ Harvolk, Eichenlaub und Hakenkreuz, S. 49.

45 Abschrift in: BHStA MK Registratur-Spalte V/1278. 
ihrer Ideen, auch zur Zusammengehörigkeit der Deutschen über alle vier Besatzungszonen hinweg beitragen. Sie werde ein "großzügiger Versuch" sein, „über Parteien und Konfessionen hinweg neue Formen des geistigen Daseins zu schaffen". In Anlehnung an die Deutsche Akademie waren zwei Abteilungen vorgesehen, eine für die Erforschung der abendländischen Kultur, eine zweite, sogenannte Erziehungsabteilung sollte die Deutschen im Umgang mit anderen Völkern schulen, internationalen Austausch organisieren und Sprachpflege betreiben. Thierfelder schlug vor, die neue Einrichtung in München anzusiedeln und die offizielle Gründung für August 1949 anläßlich des 200. Geburtstags Goethes anzuvisieren.

Die Einrichtung einer neuen Kulturorganisation erschien für Thierfelder auch dadurch geboten, daß er in beruflicher Hinsicht seit Kriegsende noch nicht wieder seinen Fähigkeiten und Erfahrungen entsprechend hatte Fuß fassen können. Ende September 1946 war er von seinem Posten als Syndikus der Bayerischen Akademie der Wissenschaften und der Münchener Universität zurückgetreten. Hintergrund war eine seit Mai 1946 in der "Süddeutschen Zeitung“ erschienene Artikelserie gewesen, die sich unter dem Titel "Theorie und Praxis“ kritisch mit dem Verlauf der Entnazifizierung in Bayern auseinandersetzte. Die Enthüllungen wiederum reflektierten die erneut seit Frühjahr 1946 in der US-Presse aufgekommene Kritik an den politischen Verhältnissen in Bayern. Dabei richtete man auf amerikanischer Seite diesmal den Fokus auf die mangelnde Überprüfung der Professoren der im April 1946 wiedereröffneten Universität, die angeblich sogar wieder Kurse über Rassetheorien abhielt, sowie auf die angeblich unter den Studenten grassierenden nationalistischen Auffassungen. ${ }^{46}$ In der Ausgabe vom 24. August 1946 griff die "Süddeutsche Zeitung" den „Fall Thierfelder“ unter Hinweis auf einen Artikel Thierfelders vom 11. Oktober 1936 in den „Münchener Neuesten Nachrichten“ über "Deutsche Kulturwerbung im Ausland" und einige inkriminierende Passagen in seinem Buch „Deutsch als Weltsprache" auf, die, isoliert betrachtet, Thierfelder tatsächlich als Propagandist des NS-Regimes erscheinen ließen. ${ }^{47}$

Mit diesen Enthüllungen zerschlugen sich auch Thierfelders Ambitionen auf eine politische Karriere: Er war immerhin 1946 für die CSU, in welcher er sich vor allem für Jugendfragen engagierte, in die bayerische Verfassunggebende Landesversammlung gewählt worden, nun aber nominierten ihn seine Parteigenossen nicht mehr für die anstehenden Landtagswahlen. Kultusminister Alois Hundhammer beschied ihm, das jegliche Einstellung im Kultusministerium oder den ihm unterstehenden Institutionen ausgeschlossen sei, solange Thierfelders Entnazifizierungsverfahren nicht abgeschlossen sei. Dies empörte Thierfelder um so mehr, als der letzte Generalsekretär der Akademie, Schmitz, mittlerweile als Journalist bei einer amerikanischen Zeitung untergekommen war, während er als an-

46 Tent, Mission on the Rhine, S. $80 \mathrm{ff}$.

47 So hatte Thierfelder in den Münchener Neuesten Nachrichten beispielsweise geschrieben, man müsse Ausländern klarmachen, "daß der Nationalsozialismus nicht eine Erfindung, sondern Durchbruch eines deutschen Urwesens ist - ein elementarer Vorgang von unabänderlichem Zwang.“ 
geblicher Nationalsozialist geächtet wurde. ${ }^{48} \mathrm{Mit}$ ihm hatte die „Süddeutsche Zeitung" einen Zeitgenossen anvisiert, der ein nicht sehr prominentes und krasses Beispiel für das Überleben der NS-Eliten in der neuen Zeit abgab, sondern eher als ein typischer „Mitläufer" anzusehen war. Thierfelder hatte zwar ursprünglich die Machtübernahme der Nationalsozialisten willkommen geheißen, da sie das Ende der ungeliebten Weimarer Republik bedeutete, und sich nicht zuletzt in der Hoffnung angepaßt und mit dem Regime kollaboriert, dadurch die Deutsche Akademie ausbauen zu können. Er hatte sich jedoch stets nur partiell mit den Zielen des Regimes und seiner Ideologie identifiziert und nie versucht, der NSDAP oder anderen NS-Formationen beizutreten. ${ }^{49}$ Dennoch verfolgte der Schatten der NS-Zeit Thierfelder für zweieinhalb Jahre und blockierte seine Aussichten auf dauerhafte Anstellung im Staatsdienst. So verhinderte das in München anhängige Verfahren und der Wirbel um seine Person im Jahre 1949 zunächst auch seine geplante und vom hessischen Kultusminister befürwortete Einstellung als Leiter der Hochschulabteilung im Wiesbadener Kultusministerium. ${ }^{50}$ Thierfelder mußte bis Februar 1949 warten, bis ein Münchener Spruchkammerverfahren ihn in zweiter Instanz, welche das Urteil der ersten Instanz vom November 1948 bestätigte, als gänzlich unbelastet einstufte, ja ihn sogar nun nach Thierfelders eigenen Worten „als Mann echten Widerstands" bezeichnete. ${ }^{51}$ Folglich schlug Thierfelder sich in den Jahren 1946-1949 wieder als Publizist durch ${ }^{52}$ und konnte seine Energien auf die Wiedererrichtung einer kulturpolitischen Zentraleinrichtung konzentrieren.

Ermutigt durch das Echo auf sein Rundschreiben vom 30. November 1948 an die Ehemaligen der Deutschen Akademie, das, wie er in seinem zweiten Rundschreiben vom Februar 1949 bemerkte, größtenteils positiv gewesen sei, versuchte Thierfelder ab Februar 1949, die Nachfolgeorganisation konkret vorzubereiten. Die neue Organisation sollte, so Thierfelder in seinem zweiten Rundschreiben, den geistigen Zusammenhang in Deutschland stärken und die Beziehungen zu nichtdeutschen Völkern fördern, wobei sich Wiesbaden als Sitz der neuen Institution wegen seiner zentralen Lage anbiete. ${ }^{53} \mathrm{Daß}$ sich das Zentrum von Thierfelders Aktivitäten von München nach Wiesbaden verschob, war aber weniger der angeblich zentraleren Lage der hessischen Hauptstadt geschuldet. Entscheidender war vielmehr, daß Thierfelder mit seinem ersten Rundschreiben auch Magnus an-

48 Einige Dokumente hierzu befinden sich in Thierfelders Personalakte, in: BHStA MK 44433.

49 Vgl. Kapitel V. Seine Personalakte im Berlin Document Center des Bundesarchivs Berlin weist ihn nur seit 1933 als Mitglied der Reichsschrifttumskammer aus. Die Mitgliedschaft zu dieser war notwendig, um als Publizist im Dritten Reich arbeiten zu können.

50 Schriftliche Auskunft des Hessischen Hauptstaatsarchivs in Wiesbaden an den Autor vom 10. 8. 2000.

51 BHStA MK44433, Schreiben Thierfelders and Hundhammer, 13. 11. 1948; BAK B307/ 118, Schreiben Thierfelders an Magnus, 3.6. 1949.

52 Vgl. Franz Thierfelder, Volk, Nation, Staat, Aachen 1947; ders., Die deutschen Universitäten heute und morgen. Ein kritischer Beitrag zur Frage der Trennung von Forschung und Lehre sowie anderen akademischen Gegenwarts- und Zukunftsaufgaben, Aachen 1947; ders., Die Grenzen Europas. Begriff und Wesen Europas und der abendländischen Kultur, Köln 1948.

53 BAK B307/118, Rundschreiben Nr. 2 Thierfelders, Februar 1949. 
gesprochen hatte, den letzten Direktor der Reichsrundfunkgesellschaft in der Weimarer Republik, der in dieser Eigenschaft auch außerordentlicher Senator der Deutschen Akademie gewesen war, allerdings 1933 aus beiden Positionen entfernt worden war. Nach neunzehnmonatiger Inhaftierung durch die neuen nationalsozialistischen Machthaber, die einen Schauprozeß gegen die Verantwortlichen des Weimarer Rundfunks unter dem Vorwand der Veruntreuung öffentlicher Gelder angestrengt hatten, der schließlich im Juni 1935 wegen der Haltlosigkeit der Vorwürfe mit einem Freispruch endete, ${ }^{54}$ verbrachte Magnus die restlichen Jahre des Dritten Reiches als Kaufmann in Wiesbaden. Die Amerikaner holten ihn $1945 \mathrm{zu}$ nächst in die Bezirksregierung in Wiesbaden, im darauffolgenden Jahr wurde er Ministerialdirektor im hessischen Wirtschaftsministerium. ${ }^{55}$ Magnus und Thierfelder waren nicht nur durch die gemeinsame Akademievergangenheit verbunden, sondern auch durch ein gemeinsames Interesse am Rundfunk. Während Magnus seit 1948 Vorsitzender des Hessischen Rundfunkrates war und damit an seine Tätigkeit in der Weimarer Republik anknüpfte, hatte Thierfelder bereits in den dreiBiger Jahren eine engere Zusammenarbeit mit der Reichsrundfunkgesellschaft angestrebt, da er den Rundfunk als das zeitgemäße Mittel zur Sprachpflege ansah. ${ }^{56}$ Magnus war jedenfalls ein einflußreicher Mann in der hessischen Regierung mit guten Kontakten zur Wirtschaft und einer politisch weißen Weste. Er verwendete sich nicht nur bei Kultusminister Stein für die Einstellung Thierfelders als Referent für Hochschulfragen, ${ }^{57}$ sondern fand auch Gefallen an Thierfelders Idee einer zentralen deutschen Kulturorganisation. Zusammen initiierten sie im Februar 1949 als ersten Schritt den „Wiesbadener Arbeitskreis“, dessen Gründungsversammlung am 13. Februar 1949 in der hessischen Landeshauptstadt stattfand. Unter den 14 anwesenden Personen befanden sich neben Thierfelder, Fehn, Magnus, Eckert und Meier noch der Germanist Wolfgang Stammler sowie Heinz Kloss, ein ehemaliger Mitarbeiter des DAI sowie der Historiker Paul Wentzcke, der ebenso wie Kloss in der Weimarer Republik und im Dritten Reich zu Forschungen über das Grenz- und Auslandsdeutschtum hervorgetreten war. Dabei war Thierfelder der drängendere Part, der Magnus wegen seines Renommees und seiner Beziehungen offenbar stärker in die kulturpolitischen Tätigkeiten einzubinden versuchte, als diesem lieb war. Denn Mitte Juni 1949 beschwerte sich Magnus bei Thierfelder darüber, daß ihm der Vorsitz im Wiesbadener Arbeitskreis angetragen worden sei, obwohl er im vorhinein erklärt habe, wegen seiner anderweitigen großen Arbeitsbelastung nicht interessiert zu sein. ${ }^{58}$

54 Vgl. hierzu Ansgar Diller, Rundfunkpolitik im Dritten Reich, München 1980, S. $128 \mathrm{ff}$.

55 Zu Magnus vgl. Hessischer Rundfunk (Hrsg.), Kurt Magnus. 19 Beiträge zu seinem Lebenswerk, Frankfurt/M. 1957.

56 Vgl. Franz Thierfelder, Sprachpolitik und Rundfunk, Berlin 1941.

57 In einem Schreiben vom 3. 6. 1949 an Magnus führte Thierfelder Beispiele für seine antinazistische Gesinnung als Grundlage für Magnus' anstehende Besprechung mit seinen Kollegen über die Einstellung Thierfelders im hessischen Kultusministerium auf. In: BAK B307/118. Tatsächlich erhielt Thierfelder aber nur einen Werkvertrag für den Zeitraum vom 15. 3. bis 15.11. 1949. Brief des Hessischen Hauptstaatsarchivs an den Autor, 10. 8. 2000.

58 BAK B307/118, Brief von Magnus an Thierfelder, 22. 6. 1949. 
Der Wiesbadener Arbeitskreis sollte zunächst, wie aus einem Sprechzettel hervorgeht, den Thierfelder sich als Gedankenstütze zur Gründungsversammlung angefertigt hatte, die Möglichkeiten des Aufbaus einer unabhängigen Kulturorganisation eruieren. ${ }^{59} \mathrm{Die}$ Gründung einer solchen wurde als nötig erachtet, da andernfalls die Gefahr des „deutschen Verfalls“ durch „Zonenpartikularismus“ und „Parteibetrieb“ drohe, der wiederum einhergehen könne mit dem Wiederaufleben nationalistischer Ressentiments, allgemeiner „Demoralisierung “ und „Materialisierung“. Das Kernziel der zu errichtenden Kulturorganisation müsse sein, das deutsche Volk durch Erforschung der abendländischen Kulturgrundlagen und durch Erziehung zu einem gefestigten, vollwertigen Mitglied der europäischen Völkerfamilie zu machen. Die Hauptaufgabe der neuen Organisation sei also innerdeutsch, „aber unablässig mit Blick nach außen“. Obwohl es auf dem Sprechzettel hieß „Keine Deutsche Akademie!“, sondern Errichtung eines „Deutschen Konvents für Kulturforschung und Erziehung “, lehnte sich die skizzierte organisatorische Struktur eng an jene der Deutschen Akademie an. Eine Forschungsabteilung sollte sich der „Untersuchung der abendländischen Kulturgrundlagen in internationaler Zusammenarbeit“ widmen, eine „Erziehungsabteilung“ würde Erwachsenenbildung, Sprachpflege, Erziehung im Umgang mit Völkern und Kulturaustausch, „soweit von außen gewünscht“, betreiben.

In Thierfelders Stichpunkten tauchten vertraute Schlagworte des damaligen Diskurses auf, die auf eine eher konservative Ausrichtung des geplanten Unternehmens deuteten. Es orientierte sich, zumindest in der von Thierfelder anvisierten Form, ideell am konservativ-antidemokratischen, kulturpessimistischen Denken der zwanziger Jahre, das sich in Teilen des deutschen Widerstands wiederfand, und auch in den ersten Nachkriegsjahren noch viele Anhänger im Bildungsbürgertum hatte: Parlamentarische Demokratie wurde nach wie vor mit egoistischer Parteienherrschaft gleichgesetzt, die wiederum Synonym für Uneinigkeit und Verfolgung purer materieller Interessen war. Zugleich stand man der "Masse“, welche erzogen und geführt werden müsse, skeptisch gegenüber. 60

Thierfelder präsentierte ein Programm, das große Ähnlichkeit mit den von ihm und Zwiedineck-Südenhorst ventilierten Ideen für eine Nachfolgeorganisation der Deutschen Akademie vom Sommer 1945 hatte. Parallelen zur Deutschen Akademie gab es nicht nur in der geplanten organisatorischen Struktur, also in der Verknüpfung von Forschungsarbeit und Verbreitung dieser Erkenntnisse durch eine „praktische“ Abteilung. Auch die grundsätzliche Idee, in Zeiten der vermeintlichen Auflösung der nationalen Bande innerhalb Deutschlands eine gesamtdeutsche Kulturorganisation als Klammer zu gründen, erinnerte stark an den Tenor der Gründungsbestrebungen für die Deutsche Akademie in den Jahren 1923 bis 1925 . Allerdings waren die Bestrebungen in den zwanziger Jahren dahingehend ausgerichtet gewesen, den Deutschen ein einheitliches Kulturbewußtsein

59 BAK B307/118, Zusammenkunft in Wiesbaden, 13. 2. 1949.

$60 \mathrm{Vgl}$. Hans Mommsen, Der lange Schatten der untergehenden Republik. Zur Kontinuität politischer Denkhaltungen von der späten Weimarer Republik zur frühen Bundesrepublik, in: Die Weimarer Republik 1918-1933. Politik-Wirtschaft-Gesellschaft, hrsg. von Karl Dietrich Bracher u.a., Bonn ${ }^{3} 1998$, S. 552-586. 
zu vermitteln als Voraussetzung für ein selbstbewußteres Auftreten nach außen. Jetzt hingegen war das angestrebte Erziehungsziel eine eher „abendländische“ denn rein deutsche Gesinnung mit stärkeren selbstkritischen Tönen. An die Stelle der Idee des vormals verabsolutierten Nationalstaats trat nach 1945 für etwa eine Dekade bei vielen konservativen Denkern die Vision der angeblichen christlichwesteuropäischen Schicksalsgemeinschaft der Völker. Der Abendlanddiskurs war im übrigen durchaus populär unter den ehemaligen Anhängern und Propagandisten der Konservativen Revolution, wie die publizistischen Aktivitäten von Hans Zehrer und Giselher Wirsing nach 1945 zeigten. In ihm konnten sich die Deutschen in scharfer Abgrenzung zum „orientalischen“ Sowjetkommunismus (wie auch dem angeblich krassen, kulturlosen Materialismus der USA) wiederfinden, ohne des Rückfalls in nationalistischen Größenwahn verdächtigt zu werden. Diese „abendländische“ Wendung war eine Konzession an die Zeitumstände, ihr lag aber auch ein gewisser Lernprozeß zugrunde. Solange es noch keinen deutschen Nationalstaat gab und eine solche Perspektive Unbehagen, ja Furcht bei Deutschlands Nachbarn auslösen würde, war eine „abendländische“ Gesinnung sozusagen die Auffangidentität. 61

Der Gedanke, die Deutschen seien unerfahren im Umgang mit anderen Völkern, da sie zwischen der Negation ihrer eigenen kulturellen Leistungen gegenüber dem Ausland einerseits und auftrumpfendem, unsensiblen Auftreten andererseits schwankten, und müßten daher entsprechend erzogen werden, war im übrigen ein Leitmotiv Thierfelders seit den zwanziger Jahren. Schon 1931 schrieb er über das Verhältnis der Deutschen zum Ausland: „Blindes Überschätzen eigener Kultur stand unwürdigem Preisgeben des Volkstums zugunsten eines als besser, vornehmer empfundenen Volkstums gegenüber, einzigartiges Einfühlungsvermögen kennzeichnete den Charakter ebenso wie unduldsame Kritik und Schulmeisterei."62 1943 fungierte Thierfelder sogar als Herausgeber einer Schriftenreihe mit dem Titel „Umgang mit Völkern“, zu der er die Bände über „Deutsche“ und „Balkanier" beisteuerte. Seine Skepsis hinsichtlich der Fähigkeit der Deutschen, mit anderen Völkern ein auskömmliches Verhältnis aufzubauen, war natürlich durch die Erfahrungen der NS-Diktatur noch verstärkt worden. So kam er auf dieses Thema bereits im Februar 1946 zurück, als er vor Studenten der Münchener Universität einen Vortrag über die Deutschen und ihren Umgang mit anderen Völkern hielt. ${ }^{63}$ In diesem behauptete er, ohne auf die vorangegangenen Jahre der

$61 \mathrm{Vgl}$. Axel Schildt, Zwischen Abendland und Amerika. Studien zur westdeutschen Ideenlandschaft der 50er Jahre, München 1999, S. $21 \mathrm{ff}$.

62 Thierfelder, Geistige Grundlagen kultureller Auslandsarbeit, S. 228. In seinem Bericht über seine Polenreise vom November 1936 schrieb er z.B.: „Freilich, dem deutsch-polnischen Ausgleich stehen nicht nur politische, sondern auch psychologische Hemmnisse entgegen. Gewisse Minderwertigkeitskomplexe bei den Polen, gewisse auf völliger Unkenntnis der polnischen Leistungsfähigkeit beruhende Überwertigkeitskomplexe beim Deutschen sind vielleicht noch hemmender als die politischen Schwierigkeiten. Beides ist durch psychologische Aufklärungsarbeit hier wie dort zu überwinden und ich glaube, daß hier Deutschland mehr versäumt hat als Polen." In: IfZ ED 98, Bericht über meine Vortragsreise in Polen 2. 11.-14. 11. 1936.

63 Süddeutsche Zeitung, 22. 2. 1946. 
NS-Diktatur explizit Bezug zu nehmen, daß nur die planmäßige Erziehung zur Selbsterkenntnis und Selbstkritik sowie das systematische Studium der „fremden Volksseelen“, denen man eine "gewisse Liebe“ entgegen bringen müsse, ohne in die "Verliebtheit in das Fremde" zu verfallen, es ermöglichen werde, Deutschland einen Platz in Europa zu sichern. Das gestörte Verhältnis der Deutschen zu ihren Nachbarn resultierte für ihn aus der Sprunghaftigkeit des deutschen Charakters, der Unfähigkeit zum Kompromiß und einem Mangel an Höflichkeit. Dies waren Untugenden, welche laut Thierfelder die negativen Ausprägungen von typisch deutschen Eigenschaften wie Gerechtigkeitssinn, Hingabe und Wahrheitsliebe waren.

Ein zweites Treffen des Arbeitskreises fand Ende März 1949 in Wiesbaden statt. Nun ergriff Magnus das Wort und dankte zunächst Thierfelder für seine Gründungsinitiative und gestand ein, zunächst skeptisch gewesen zu sein.64 Die Zielsetzung des Vereins, die nun von Magnus skizziert wurde, entsprach jener Thierfelders auf der Gründungsversammlung, also einem drohenden Zerfall der Nation kulturpolitisch entgegenzuwirken. Die zu gründende Organisation sollte nun „Deutsche Gesellschaft für geistige Zusammenarbeit" heißen und Gelehrte wie Kräfte der Wirtschaft zusammenführen. Doch werde man zunächst mit der praktischen Arbeit beginnen und erst wenn konkrete Arbeitsergebnisse erzielt seien, die offizielle Gründung in aller Öffentlichkeit vornehmen. Eine Vorgehensweise, die möglicherweise in Erinnerung an die Erfahrungen der Gründungsphase der Deutschen Akademie vereinbart worden war, hatte diese sich doch der Öffentlichkeit präsentiert, ohne ein klares Arbeitsfeld vorweisen zu können. Erst wenn man einige Leistungen erbracht habe, so Magnus, sei es auch möglich, die Wirtschaft für eine Finanzierung zu gewinnen, denn deren Spendenwilligkeit sei momentan durch eine wahre Gründungsflut wissenschaftlicher Einrichtungen wie der Max-Planck-Gesellschaft, der Notgemeinschaft der Deutschen Wissenschaft und der Fraunhofer-Gesellschaft ausgereizt. Der Wiesbadener Arbeitskreis wolle zunächst vor allem den Kontakt zur Gesellschaft für Deutsche Sprache in Lüneburg, der 1947 gegründeten Nachfolgeorganisation des Allgemeinen Deutschen Sprachvereins, intensivieren, da er an der Sprachpflege im engeren Sinne interessiert sei. Die Sprache sah man in Wiesbaden unter dem Einfluß Thierfelders als das nach wie vor stärkste Band und letztlich wesentliches Merkmal, das die Deutschen über Partei- und Zonengrenzen hinweg verband und ihnen erst die Eigenschaften eines spezifischen Volkes zuschrieb. ${ }^{65}$ Die Sprache konnte aber ihre einigende Funktion in den Augen des Wiesbadener Arbeitskreises nur ausüben, wenn sie auch weiterhin auf einem einheitlichen Vokabular und allgemein anerkannten Regeln ihrer Anwendung basieren würde.

64 B307/118, Ansprache Magnus' vom 28. 3. 1949, in: Wiesbadener Arbeitskreis, Monatsberichte Nr. 1.

65 Ausführungen über die Sprache als wichtigstes Merkmal zur Bestimmung eines Volkes im Sinne Schmidt-Rohrs, aber auch über angebliche Auflösungserscheinungen des Sprachkonsenses in Deutschland als Folge des Zweiten Weltkrieges finden sich beispielsweise bei Thierfelder, Volk - Nation - Staat, S. $10 \mathrm{f}$. 
Am 25. Mai wurde der Wiesbadener Arbeitskreis ins Vereinsregister beim Amtsgericht Wiesbaden eingetragen. Als erster Vorsitzender fungierte Magnus, als zweiter Kurt Beyer, Hauptgeschäftsführer der Frankfurter Industrie- und Handelskammer, zum dritten Vorsitzenden wurde Wentzcke gewählt, der ein früherer Senator der Deutschen Akademie war. Seit Juni 1949 gab der Wiesbadener Arbeitskreis sogenannte „Nachrichten und Betrachtungen“ heraus, die bis 1950 in sechs hektographierten Ausgaben an die Mitglieder verschickt wurden. Sie enthielten Zusammenfassungen der insgesamt fünf Tagungen des Arbeitskreises, Informationen über andere kulturpolitische Einrichtungen und Berichte über kulturelle Kontakte Deutschlands zum Ausland. Diese wurden ebenso wie die Treffen des Arbeitskreises durch Spenden der hessischen Wirtschaft und Unterstützung des hessischen Wirtschaftsministeriums ermöglicht. So stellte Magnus Thierfelder, der seit Gründung des Arbeitskreises als dessen Generalsekretär fungierte, zwei Sekretärinnen seines Ministeriums zur Verfügung. Mitte 1949 besaß der Arbeitskreis nach eigenen Angaben 180 Mitglieder, unter ihnen 25 Ausländer ${ }^{66}$ und ca. zwei Dutzend ehemalige Angehörige der Deutschen Akademie ${ }^{67}$, wie etwa ExHauptgeschäftsführer Fehn, der im Krieg bis zum Oberst avanciert war, Dora Schulz, Eckert, Meier und der Germanist Borcherdt. Allerdings beschränkte sich die Mitgliedschaft bei den meisten auf eine bloße Erklärung, die Ziele des Vereins fördern zu wollen. Die große Mehrzahl der Mitglieder war der Öffentlichkeit unbekannt, da es sich um Lehrer, kleinere Unternehmer wie den Verleger Otto Luken, ehemalige Kulturfunktionäre wie Karl Epting, einzelne Beamte aus hessischen Ministerien und Rechtsanwälte handelte. Zu den wenigen bekannteren Persönlichkeiten des Arbeitskreises zählten der Soziologe Hans Freyer, in der Weimarer Republik einer der Vordenker der Konservativen Revolution, der nach 1945 mit zivilisationskritischen Schriften hervortrat und nach Verlust seines Leipziger Lehrstuhls in Wiesbaden für die Brockhaus-Redaktion arbeitete, und Kultusminister Stein.

Im Verlaufe des Jahres 1949 expandierten die Aktivitäten und Interessengebiete des Wiesbadener Arbeitskreises. Doch handelte es sich hierbei eher um ein Abtasten zukünftiger kulturpolitischer Tätigkeitsfelder und den Versuch, sich in der entstehenden kulturpolitischen Landschaft der Bundesrepublik irgendwie zu positionieren, als um ein klar definiertes Programm. Die Anfänge dieser zunächst großzügig gedachten, aber auf unsicherem Fundament gegründeten Organisation erinnerten also fatal an die ersten Jahre der ebenfalls mit großem Anspruch gegründeten Deutschen Akademie. Der Tätigkeitsbericht des Wiesbadener Arbeitskreises vom Juli $1950^{68}$ führte schließlich sieben Arbeitsfelder auf, die jedoch zumeist nicht über das Planungsstadium auf dem Papier hinausgekommen waren und relativ unkoordiniert nebeneinanderstanden. Er erweckte den Eindruck, als hätten die Gründer Signale in alle Richtungen ausgesendet und jede ausgestreckte Hand willig ergriffen, um ja ein weites kulturpolitisches Spektrum vorweisen zu

66 Tatsächlich handelte es sich zumeist um Auslandsdeutsche.

67 BAK B307/118, Arbeitsbericht des Wiesbadener Arbeitskreises e.V. für die Zeit vom Februar 1949 bis Juni 1950, 25. 7. 1950.

68 Ebenda. 
können: Die anvisierte „Zentralstelle für Sprachkultur“ wies als einzig greifbares Ergebnis die Herausgabe von Thierfelders Ratgeber „Wege zum besseren Stil“ auf, während sich eine Zusammenarbeit mit der Gesellschaft für Deutsche Sprache und der 1949 gegründeten Akademie für Sprache und Dichtung in Darmstadt noch nicht ergeben hatte. Die "Arbeitsstelle für praktische Völkerpsychologie“ bot vergeblich der Frankfurter Handelskammer Vorbereitungskurse für ins Ausland reisende Vertreter der deutschen Wirtschaft an. Auf diesem Gebiet konnte man einzig eine Neuauflage von Thierfelders Schriftenreihe „Umgang mit Völkern" aus dem Jahre 1943 vorweisen, ursprünglich vermutlich eine Auftragsarbeit für die Parteikanzlei, ${ }^{69}$ die nun im Nürnberger Verlag Luken \& Luken erschien. Die ersten Bände boten Nationalporträts von Briten, Brasilianern, Arabern, Chinesen, Niederländern und Italienern. Die „Arbeitsstelle für abendländische Kulturforschung" kam über einen "Generalplan für Forschungsarbeiten" nicht hinaus. Die „Arbeitsstelle für Methodik des fremdsprachlichen Unterrichts und geistigen Austausch“, vom späteren ersten Geschäftsführer des neuen Goethe-Instituts, Helmuth Brückmann, geleitet, organisierte immerhin im Oktober 1949 eine Tagung von 130 Neuphilologen in Nürnberg, auf der Methoden und Probleme des fremdsprachigen Unterrichts in Deutschland erörtert wurden. „Die Arbeitsstelle zur Erforschung des europäischen Volksliedes“ war eine Totgeburt, da eine Zusammenarbeit mit dem Deutschen Volksliedarchiv in Freiburg letztlich nicht zustande kam. In München kam es immerhin zur Wiedergründung des vormaligen "India Institute“ der Deutschen Akademie durch den Wiesbadener Arbeitskreis, das den akademischen Austausch zwischen Westdeutschland und Indien in sehr bescheidenem Umfang wieder aufnahm. Schließlich führte der Arbeitsbericht noch eine Abteilung für Theater und Musik auf, die allerdings nie aktiv wurde.

Auf dem vierten Treffen des Arbeitskreises Mitte November 1949 wurde eine Kursänderung beschlossen. Im Frühjahr 1949 hatte man sich noch dafür ausgesprochen, erst Leistungen vorweisen zu wollen, um dann an die Öffentlichkeit zu gehen. Nunmehr glaubten Magnus und Thierfelder jedoch, daß man die Wirtschaft und die öffentliche Hand - die Hoffnungen ruhten hier auf der 1948 eingerichteten ständigen Kultusministerkonferenz der Länder -, nur zur Finanzierung gewinnen könne, wenn die anvisierte Kulturorganisation schon auf „eindrucksvolle Weise“ gegründet worden sei. Die Gründung dieser „Allgemeinen Deutschen Kulturgesellschaft“ sollte daher beim nächsten Treffen des Arbeitskreises in Angriff genommen werden. ${ }^{70}$ Die Ziele dieser Gesellschaft, für die man einen Jahresetat von zunächst $150000 \mathrm{DM}$ für nötig erachtete, blieben recht unscharf, erinnerten aber nach wie vor an die Intentionen, mit denen die Deutsche Akademie

69 In seinem Lebenslauf vom Juli 1945 behauptete Thierfelder, ihm sei 1944 von der Parteikanzlei der Aufbau und die Leitung einer großen Organisation zur besseren völkerpsychologischen Erziehung der Deutschen angeboten worden. Er habe die Übernahme des Projektes aber abgelehnt. Möglicherweise war die von ihm herausgegebene 15bändige Schriftenreihe „Umgang mit Völkern“ von 1943 (die er im Lebenslauf unterschlug) eine Art Vorarbeit für dieses Projekt. In: BAB R51/10116.

70 BAK B307/118, Stichworte für Dr. Magnus für den 15. 11. 1949. 
gestartet war: Durch Heranführung der Nation an ihr reichhaltiges kulturelle Erbe könne man den Deutschen wieder einen gewissen Stolz, einen Daseinszweck und Zusammenhalt vermitteln. Dieser würde sie nicht nur über die schwierigen materiellen Lebensbedingungen hinwegtrösten, sondern sie zugleich gegen erneute, aus der Frustration über die wenig erbauliche Gegenwart resultierende nationalistische Versuchungen imprägnieren. Zugleich sei die deutsche Kultur das einzige Gut, mit dem Deutschland sich auch international wieder Ansehen verschaffen könne. ${ }^{71}$

Thierfelder arbeitete parallel zu seinen Aktivitäten im „Wiesbadener Arbeitskreis" im Rahmen eines Werkvertrages für Kultusminister Stein zwischen März und November 1949 an einer Denkschrift über die Koordination der Kulturpolitik der Länder im Rahmen der Kultusministerkonferenz.72 Diese Tätigkeit war ein wichtiges Standbein für seine Bemühungen um eine zentrale deutsche Kulturorganisation. Im November 1949 reichte die hessische Regierung schließlich bei der Kultusministerkonferenz eine Denkschrift zur Errichtung einer „Deutschen Gesellschaft für geistige Zusammenarbeit" ein, die vermutlich ganz wesentlich Thierfelders Handschrift trug. Thierfelder begleitete den hessischen Kultusminister zum Treffen der Kultusminister in Düsseldorf Anfang Dezember 1949, auf der das Projekt diskutiert werden sollte. Den Hintergrund bildeten Spannungen zwischen den Ländern und der soeben konstituierten ersten Bundesregierung. Die Länder hatten schon auf der vorangegangenen Kultusministerkonferenz in Bernkastel Mitte Oktober 1949 gefordert, die neue westdeutsche Regierung müsse die Kulturhoheit der Länder respektieren. ${ }^{73}$ Die Bundesregierung wiederum wollte außer dem Bundesrat keine staatsrechtlichen Organe dulden, die durch Zusammenschluß mehrerer Bundesländer entstehen und gleichsam eine dritte Ebene zwischen Gliedstaaten und Zentralregierung bilden konnten. ${ }^{74}$ Wie aus dem Protokoll der Düsseldorfer Konferenz hervorgeht, sahen die Länder offenbar ihre Kulturhoheit durch das neu entstandene Bundesinnenministerium gefährdet und suchten durch eine eigene Initiative diese Gefahr für den Bereich der auswärtigen Kulturbeziehungen $\mathrm{zu}$ bannen, indem sie argumentierten, diese könnten besser von einer nichtstaatlichen Organisation gelenkt werden. ${ }^{75}$ Allerdings wurde die Diskussion vertagt, und Anfang 1950 zog.die hessische Regierung ihren Vorschlag gänzlich zurück. ${ }^{76}$ Ursache hierfür war vermutlich der Umstand, daß sich die Befürchtungen, das Bundesinnenministerium oder andere Bundesres-

71 Ebenda, Allgemeine Deutsche Kulturgesellschaft: Aufgabe und Verwirklichung, Juni 1950.

72 Brief des Hessischen Hauptstaatsarchivs an den Autor, 10. 8. 2000.

73 Vgl. Winfried Müller, Die Gründung der Ständigen Konferenz der Kultusminister der Bundesrepublik Deutschland, in: Historisches Jahrbuch, 114 (1994), S. 76-106.

74 Die Kabinettsprotokolle der Bundesregierung. Bd. 1: 1949, hrsg. vom Bundesarchiv, Boppard 1982, S. 155 (Kabinettssitzung vom 25. 10. 1949).

75 In diesem Sinne äußerten sich jedenfalls die nordrhein-westfälische Kultusministerin Teusch und Stein auf der Konferenz, in: BHStA MK 65977, Niederschrift der Tagung der Kultusministerkonferenz in Düsseldorf am 2./3.12. 1949.

76 Vgl. die Protokolle der Kultusministerkonferenz in: BHStA MK 65977. 
sorts könnten die Länder kulturpolitisch bevormunden, rasch als unbegründet erwiesen.

Das nächste Treffen des Wiesbadener Arbeitskreises Ende Januar 1950, als Sitzung des Vorbereitungsausschusses zur Gründung der Allgemeinen Deutschen Kulturgesellschaft deklariert, fand folglich unter nicht gerade günstigen Umständen statt, die zu dem ambitionierten Vorhaben, das in Angriff genommen werden sollte, stark kontrastierten. Der Versuch, die Kultusministerkonferenz für die zu gründende Organisation einzuspannen, war fehlgeschlagen. Magnus berichtete zudem, daß mit Spenden aus der Wirtschaft vorerst auch nicht zu rechnen sei. Man beschloß daher, zwei weitere Pfade zu verfolgen. Fehn schlug vor, die Deutsche Akademie e.V. wiederzugründen, um damit an das immer noch vom bayerischen Staat verwaltete Vermögen der 1945 aufgelösten Institution als Startkapital für die neue Organisation heranzukommen. Magnus wollte außerdem hinsichtlich finanzieller Unterstützung die Bundesregierung kontaktieren. ${ }^{77}$

Als sich das Bundesinnenministerium unter Hinweis auf die Kulturhoheit der Länder Anfang Februar ebenfalls desinteressiert zeigte, ${ }^{78}$ wurde die Option der Wiedergründung der Deutschen Akademie zur einzigen Chance überhaupt, der geplanten Allgemeinen Deutschen Kulturgesellschaft finanziell in den Sattel zu helfen. Zugleich müßte diese, so Thierfelder an Magnus, ihr Tätigkeitsfeld vermutlich vor allem auf Fragen der Sprachpflege und Sprachförderung eingrenzen, um nicht mit der Kulturhoheit der Länder zu kollidieren, da die Pflege der Sprache eine gesamtdeutsche Angelegenheit sei, gegen welche die Länder schlecht etwas einwenden könnten. ${ }^{79}$ Eine Aufzeichnung Thierfelders und Magnus' über die "Allgemeine Deutsche Kulturgesellschaft - Aufgabe und Verwirklichung " 80 vom Juni 1950 sah neben einem fünfköpfigen Vorstand, einem Kuratorium und einem 100köpfigen Senat aus 70 Westdeutschen und 30 noch zu bestimmenden Ostdeutschen zwei Abteilungen vor. Die eine sollte eine „Zentralstelle für Sprachkultur" in Wiesbaden sein, die sich mit Fragen der Rechtschreibung, Stilkunde, Aspekten von Rundfunk und Sprache, internationaler Sprachstatistik und der Methodik des Sprachunterrichts befassen würde. Die andere war als „Arbeitsstelle für internationalen Austausch" in München gedacht und würde sich mit der Veranstaltung von Kulturdarbietungen im Ausland und Fragen der Völkerpsychologie befassen und die Arbeit des India Institutes weiterführen.

Drei Entwicklungen zeichneten sich also seit Anfang des Jahres $1950 \mathrm{ab}$, die sowohl der prekären finanziellen Situation der Wiesbadener Initiative geschuldet waren wie auch dem sich rasch zugunsten der jungen Bundesrepublik veränderndem außenpolitischen Spielraum. Diese Tendenzen waren eng miteinander verwoben und bedingten sich gegenseitig: Eine langsame, aber sichere Hinwendung der geplanten Organisation zum Ausland an Stelle der ursprünglich anvisierten

77 BAK B307/118, Niederschrift über die Sitzung des Vorbereitungsausschusses zur Gründung der Allgemeinen Deutschen Kulturgesellschaft 27.1. 1950, Protokoll vom 30.1. 1950.

78 Ebenda, Brief von Magnus an Thierfelder, 3. 2. 1950.

79 Ebenda, Brief von Thierfelder an Magnus, 8. 2. 1950.

80 Ebenda. 
Erziehung der Deutschen. Damit einher ging, sozusagen als gesamtdeutsche Aufgabe jenseits des Föderalismus, eine Konzentration der zukünftigen Kulturgesellschaft auf Aspekte der Sprachförderung. Dies führte, nicht zuletzt aus finanziellen Gründen, automatisch auch zu einer noch stärkeren Identifizierung mit der Vorgängerorganisation Deutsche Akademie.

Seit Ende 1949 begannen die Konturen einer bundesrepublikanischen Außenpolitik langsam Gestalt anzunehmen: Mit dem Petersberger Abkommen vom November 1949 gestatteten die Westalliierten der Bundesrepublik die Eröffnung von Konsulaten im Ausland, im März 1950 wurde die Bundesrepublik eingeladen, assoziiertes Mitglied des Europarates zu werden, im Juni 1950 entstand die Dienststelle für Auswärtige Angelegenheiten im Bundeskanzleramt als Kern eines künftigen Außenministeriums, mit der Revision des Besatzungsstatuts im März 1951 schließlich nahm das Auswärtige Amt offiziell wieder seine Arbeit auf. ${ }^{81} \mathrm{Da}$ mit erschien es den Initiatoren der Allgemeinen Deutschen Kulturgesellschaft zunehmend opportuner, ihre geplante Gründung mehr auf die Kulturpolitik zum Ausland zu verpflichten. Während der Föderalismus des neugegründeten westdeutschen Staates ein bundesweites Agieren auf kulturpolitischer Ebene unmöglich machte, konnte man in Wiesbaden erwarten, daß die kulturelle Vertretung nach außen wie zu Zeiten der Weimarer Republik die Angelegenheit länderübergreifender Einrichtungen sein würde. So schrieb Thierfelder im September 1950 an Magnus, „da nun das Auswärtige Amt ernstlich in Angriff genommen werden soll, müssen wir sehen, daß wir rechtzeitig ins Gespräch kommen. "82 Die Gestaltung der auswärtigen Kulturpolitik privatrechtlich organisierten Einrichtungen zu überlassen wie etwa einer "Allgemeinen Deutschen Kulturgesellschaft“ entsprach im übrigen Thierfelders seit den zwanziger Jahren geäußerten und auch im Dritten Reich hochgehaltenen Auffassung, ${ }^{83}$ daß kulturelle Begegnung und kultureller Austausch gerade auf nichtstaatlicher Ebene erfolgen solle. Laut Thierfelder verhindere eine privatrechtliche Organisation kultureller Initiativen Bürokratisierung und ermögliche einen flexibleren Einsatz der Mittel, da diese nicht so streng etatmäßig gebunden sein müßten. Zudem sei dadurch eine direkte Vereinnahmung für politische Ziele erschwert. ${ }^{84}$ Noch deutlicher wurde Thierfelder in

$81 \mathrm{Vgl}$. hierzu z.B. Ludolf Herbst, Option für den Westen. Vom Marschall-Plan zum deutsch-französischen Vertrag, München 1989, S. 63 ff. Für Aufbau und Entwicklung des Auswärtigen Amtes Hans-Jürgen Döscher, Verschworene Gesellschaft. Das Auswärtige Amt unter Adenauer zwischen Neubeginn und Kontinuität, Berlin 1995, S. 77 ff.; Charles M. Müller, Relaunching German Diplomacy. The Auswärtiges Amt in the 1950s, Münster 1996, passim.

82 BAK B307/118, Brief Thierfelders an Magnus, 10. 9. 1950.

83 So schrieb er beispielsweise in seinem Artikel vom 11.10. 1936 in den Münchener Neuesten Nachrichten, „Kulturwerbung kann nicht weit genug von der Sphäre des Staats- und Machtpolitischen entfernt liegen [...] Geistige Werbung und geistiger Austausch entziehen sich vielfach ,amtlicher' Behandlung und gedeihen nur im Kreise des Privaten."

84 Franz Thierfelder, Auswärtige Kulturpolitik, in: Nachrichten und Betrachtungen. Mitteilungsblatt des Wiesbadener Arbeitskreises e.V., September 1949, S. 1-6, in: BAK B307/ 118. 
einem Aufsatz, an dem er im Sommer 1950 schrieb, und den er, wie er Magnus mitteilte, für die „Deutsche-Akademie-Angelegenheit" zu nutzen gedachte. ${ }^{85}$

Der Aufsatz ${ }^{86}$ offenbarte sicherlich zum Teil auch den Lernprozeß, den Thierfelder seit den dreißiger Jahren durchgemacht hatte. Die Kulturarbeit der Deutschen Akademie, die seit den zwanziger Jahren letztlich der Verwirklichung außenpolitischer Ziele des Reiches vor allem auf dem Balkan gedient hatte, und die Thierfelder nicht nur gefördert, sondern sogar ganz wesentlich mitinitiiert hatte, war letztlich in eine bloße propagandistische Abschirmung einer unverhüllten Aggressionspolitik entartet. Daher wollte Thierfelder nun nur noch eine „Kulturpolitik im neuen Stil" gelten lassen, die ganz auf den Austausch im Sinne einer geistigen Horizonterweiterung von Entsender wie Empfänger abgestellt war. Er plädierte folglich für die Ersetzung des Begriffs „Kulturpolitik“ durch „Kulturarbeit", da man davon abkommen solle, den Kulturexport einer Nation ins Ausland nur als mehr oder weniger verdeckte Hilfestellung zum Erzielen wirtschaftlicher oder politischer Vorteile gegenüber den Adressaten zu sehen. Dieses Plädoyer für eine neue, angeblich von politischem Zweckdenken losgelöste Kulturpolitik war natürlich auch ein einleuchtendes Argument dafür, daß ein alsbald wieder arbeitendes Außenministerium eine nichtstaatliche Einrichtung mit der Kulturarbeit betrauen solle, oder - warum nicht gleich - Hilfestellung dabei leisten müsse, die Deutsche Akademie wieder aufleben zu lassen. Diese war laut Thierfelder dem Ideal einer nichtstaatlichen, „unpolitischen “ und auch noch kostengünstigen Kulturarbeit zumindest bis 1938 schon sehr nahe gekommen, sei aber zu Unrecht nach 1945 diffamiert worden. ${ }^{87}$

Die Verschiebung des anvisierten Tätigkeitsfeldes der geplanten Allgemeinen Deutschen Kulturgesellschaft hin zum Ausland wie auch die nach wie vor ungesicherten finanziellen Grundlagen jeglicher künftiger kultureller Aktivität führten also dazu, daß sich ab 1950 die Aktivitäten des Wiesbadener Kreises mehr oder weniger auf eine Wiedererrichtung der Deutschen Akademie reduzierten. Im letzten, zusammenfassenden Tätigkeitsbericht des Mitte 1951 sang- und klanglos eingeschlafenen „Wiesbadener Arbeitskreises“ hieß es denn auch im Gegensatz zu den vorher ventilierten großartigen Plänen, Ziel seiner Bemühungen sei die Gründung einer Nachfolgeorganisation der Deutschen Akademie gewesen, wobei man sich seit 1950 vor allem auf die Rückgewinnung des finanziellen Erbes der 1945 aufgelösten Einrichtung konzentriert habe. 88 Überspitzt formuliert kann man den Wiesbadener Arbeitskreis also als eine Arbeitsbeschaffungsmaßnahme Thierfelders in eigener Sache bezeichnen, die obsolet wurde, als die Perspektive der Wiedergründung einer Sprachförderungsinstitution nach Muster der Deutschen Akademie sich als die realistischere Option erwies.

85 Ebenda, Brief Thierfelders an Magnus, 10. 9. 1950.

86 Franz Thierfelder, Kulturpolitik im neuen Stil, in: Außenpolitik, 2 (1951), S. 217-222.

87 Ebenda, S. 219.

88 BAK B307/115, Bericht über die Tätigkeit des Wiesbadener Arbeitskreises 1949-1951, ca. Frühjahr 1951. 


\section{Thierfelders Vergangenheitspolitik}

Zunächst verschob sich der Schwerpunkt der Aktivitäten Thierfelders im Frühjahr 1950 von Wiesbaden zurück nach München. Am 12. April 1950 wurde im Münchener Vereinsregister eine „Akademie zur Wissenschaftlichen Erforschung und zur Pflege des Deutschtums/Deutsche Akademie“ eingetragen. Als Präsident fungierte Magnus, als Vizepräsident der ehemalige Senator Eckert, als Generalsekretär Thierfelder und als Hauptgeschäftsführer Fehn. ${ }^{89}$ Parallel forschten Thierfelder und Fehn seit Anfang 1950 in München nach der Hinterlassenschaft ihres einstigen Arbeitgebers. Dabei bezichtigten sie die Bayerische Akademie der Wissenschaften fälschlicherweise, in einem Akt von Nachlässigkeit die Akten der Deutschen Akademie dem Altpapier überantwortet zu haben, ${ }^{90}$ angeblich nicht zuletzt deshalb, um die Wiedergründung einer Nachfolgeorganisation zu erschweren, die Anspruch auf das finanzielle Erbe geltend machen könnte. Sie versuchten, das Bundeskanzleramt auf diesen angeblichen Skandal aufmerksam zu machen und drohten, einen Prozeß gegen den bayerischen Staat anzustrengen, der sich unrechtmäßig das Geld des ursprünglich privaten Vereins „Deutsche Akademie" angeeignet habe. ${ }^{91}$

Tätigkeitsprofil und Geschichte der alten Deutschen Akademie wie auch die angeblichen Intentionen ihres letzten Generalsekretärs wurden den Bedürfnissen des Jahres 1950/51 angepaßt: Thierfelder brachte eine stark zurechtgebogene Version der Vergangenheit der 1945 aufgelösten Einrichtung in Umlauf, die nicht so leicht zu wiederlegen war, da die Akten der Akademie zu einem Großteil bei Kriegsende verloren gegangen waren oder sich, zu einem kleineren Teil, noch in den USA befanden, von wo sie erst 1958 zurückkehrten. Hilfreich war dabei der Umstand, daß Thierfelder als unbelastet galt und sich am besten mit der Vergangenheit der Akademie auskannte. Die Akademie sollte nur in der Form wiedererstehen, in der Thierfelder sie in seiner Eigenschaft als Generalsekretär der Münchener Einrichtung in den Jahren 1928 bis 1937 befürwortet und gefördert hatte, d.h. also als eine Einrichtung, die sich ganz der kulturellen Auslandsarbeit und der Erforschung der dafür notwendigen methodischen Grundlagen widmete. Daß die Deutsche Akademie von ihrem Anspruch her sowohl vor wie nach 1937 stets auch eine Forschungseinrichtung gewesen war, die zumindest versucht hatte, in den Sektionen ihrer wissenschaftlichen Abteilung ein weites Feld wissenschaftlicher Disziplinen abzudecken, wurde hingegen stillschweigend unterschlagen. Dies wäre Wasser auf die Mühlen der Bayerischen Akademie der Wissenschaften gewesen, die sich ebenfalls Hoffnung auf die nach wie vor vom bayerischen Staat seit 1945 verwalteten 1,4 Millionen Reichsmark machte. Im Jahre 1949 hatten die

${ }^{89}$ ABAdW Deutsche Akademie Bd. 1, Auszug aus dem Vereinsregister des Amtsgerichts München vom 22. 2. 1951.

90 BAK B307/118, Aufzeichnung über die Besprechung zwischen Fehn, Thierfelder und dem Präsidenten und Syndikus der Bayerischen Akademie der Wissenschaften, 20.4. 1950.

91 PA B90/165 (KA), Schreiben von Rechtsanwalt Otto Leibrecht an das Bundeskanzleramt betr. Deutsche Akademie e.V. gegen das Land Bayern, 7. 10. 1950. 
Westalliierten schließlich die eingefrorenen Reichsguthaben freigegeben. Die Übertragung des Vermögens auf die Bayerische Akademie der Wissenschaften schien unmittelbar bevorzustehen - das bayerische Finanzministerium hatte sich am 7. Februar 1950 entsprechend positiv geäußert -, als der Wiesbadener Arbeitskreis in München mit den Nachforschungen nach dem Erbe der Deutschen Akademie begann. ${ }^{92}$

Zwecks Wiederbelebung der Deutschen Akademie, die ja immerhin 1945 von den Amerikanern als NS-Organisation verboten worden war, bedurfte es auch einer positiven Umwertung ihrer Geschichte, die erneut, wie schon im Sommer 1945, in eine gute Ära „Thierfelder“ bis Ende 1937 und eine anschließende Perversion des Unternehmens durch die unwürdigen Nachfolger geschieden wurde.

„Durch ihr entschiedenes Festhalten an den Traditionen von vor 1933 hat die Deutsche Akademie e.V. als letztes freies Kulturinstitut die demokratischen Grundsätze bis tief in die nationalsozialistische Zeit hinein aufrecht erhalten. Dies in einem geradezu vorbildlichen Kampfe gegen die bald nach der Machtergreifung einsetzenden Politisierungsversuche des Propagandaministeriums und der Volksdeutschen Mittelstelle. Bis 1938 konnten so die jüdischen und viele politisch verdächtige Mitglieder gehalten werden. Unter Ignorierung des Führerprinzips konnte die Arbeit in untadeliger, auch vom Auslande immer wieder anerkannter Weise fortgeführt werden,"

hieß es im Schreiben von Rechtsanwalt Otto Leibrecht an das Bundeskanzleramt, der den neuen Verein "Deutsche Akademie" vertrat. ${ }^{93}$ Zudem mußte der Anschein erweckt werden, als habe Thierfelder seit 1945 an nichts anderes gedacht, als eines Tages, wenn die Umstände günstig sein würden, die Deutsche Akademie als Instrument der Auslandskulturpolitik wieder aufleben zu lassen. Seine Versuche, sie zusammen mit Zwiedineck-Südenhorst im Sommer 1945 von einer Auslandskulturorganisation zu einer wissenschaftlichen, rein innerhalb Deutschlands wirkenden Einrichtung umzuformen, überging er daher ebenso wie seine damalige Skepsis über den politisch belasteten Namen und sein schließliches Desinteresse ab Herbst 1945, überhaupt für ihrem Erhalt weiter zu kämpfen. Sein damaliger Mitstreiter Zwiedineck-Südenhorst gab hingegen gegenüber der Bayerischen Akademie der Wissenschaften an, daß sie beide 1945 ein Wiederaufleben der mehr als suspekt gewordenen Einrichtung für undenkbar gehalten hätten.94

Nun ging es jedoch darum, eine möglichst überzeugende personelle wie inhaltliche Kontinuität zwischen der 1945 untergegangenen Institution und dem neugegründeten Verein „Deutsche Akademie“ zu konstruieren. Folglich lud Thierfelder im Februar 1951 ehemalige Lektoren der Akademie zum ersten Nachkriegstreffen in München ein. Etwa 70 frühere Lektoren erschienen tatsächlich am 17./ 18. März 1951 zum Treffen in der bayerischen Landeshauptstadt. Ganz im Gegensatz zu seiner kritischen Einstellung gegenüber der Deutschen Akademie und ihrer Auslandsarbeit sowie den Chancen zukünftiger kulturpolitischer Betätigung im Ausland, die Thierfelder als kommissarischer Generalsekretär und Abwick-

92 Vgl. hierzu die Schriftstücke aus den Jahren 1948 bis 1950 in: AdBAdW Deutsche Akademie Bd. 1.

93 PA B90/165 (KA), Schreiben vom 7. 10. 1950.

94 AdBAdW Deutsche Akademie Bd. 2, Besprechung betreffend die ehemalige Deutsche Akademie in der Bayerischen Akademie der Wissenschaften, 22. 3. 1951. 
lungsbeauftragter 1945 an den Tag gelegt hatte, hieß es nun im Einladungsschreiben an die Lektoren vom 14. Februar 1951:

„Seit dem 31. 12. 1937, da ich meine Arbeit aus Gründen politischer Überzeugung und praktischer Erfahrung als Generalsekretär niederlegte, habe ich an die Stunde gedacht, in der ich sie wieder aufnehmen würde. 1945, als ich zur kommissarischen Abwicklung der Deutschen Akademie zurückgerufen wurde, schien sie gekommen zu sein, aber ich erkannte sehr bald, daß das eine Täuschung war. Deutsche, die den Glauben an sich selbst verloren hatten, taten das Ihre, um eine Organisation völlig zu zerstören, deren Vorhandensein sie an schwache Stunden im eigenen Leben erinnerte. Fünfeinhalb Jahre liegen nun zurück, in denen es nicht leicht war, an den Überzeugungen festzuhalten. Aber es gehörte nicht viel geschichtliche Einsicht dazu, die Wandlung vorauszusehen, die jetzt eingetreten ist: wer gesund blieb und die nötige Ausdauer besaß, mußte sie erleben. [...] Es gilt, für eine Sache öffentlich Zeugnis abzulegen, die zu Unrecht verunglimpft worden ist und es sollen Wege bedacht werden, auf denen die neue Arbeit vorwärtsschreiten wird." 95

Wollte man die ehemaligen Lektoren der Akademie zur Unterstützung einer Wiedererrichtung der untergegangenen Einrichtung gewinnen, so erschien es geraten, ihnen nicht das Gefühl zu geben, sie hätten bis 1945 einer tief mit dem NS-System und seiner Politik verstrickten Institution gedient. Die Tatsache, daß sich Abschriften des Einladungsschreibens in den Akten der Bayerischen Akademie der Wissenschaften und des bayerischen Kultusministeriums finden, zeigt, daß dieses Treffen von Thierfelder nicht nur als geselliges Beisammensein von Ehemaligen geplant war. Es war durchaus als Manifestation gedacht, um den bayerischen Einrichtungen die ungebrochene inhaltliche wie personelle Kontinuität zwischen altem und neuen Verein wie auch das seit 1945 angeblich unermüdliche Streben für seine Wiedererstehung deutlich zu machen.

Zugleich setzte Thierfelder einmal mehr seine bewährten, allerdings methodisch fragwürdigen sprachstatistischen Fähigkeiten ein, um den Nachweis zu führen, daß die deutsche Sprache keineswegs international so stark an Boden verloren habe, wie man es angesichts der Folgen von Nationalsozialismus und Weltkrieg vermuten konnte. Im Frühjahr 1950 arbeitete er an einer sprachstatistisch wie auch politisch aktualisierten Fassung seines Buches „Deutsch als Weltsprache“, die als Beitrag für die in Vorbereitung befindliche „Deutsche Philologie im Aufriß" gedacht war. Thierfelder gelang es in seinem Beitrag96, Argumente zu finden, die der deutschen Sprache gerade wegen der Folgen des Zweiten Weltkrieges eine rosige Zukunft hinsichtlich ihrer internationalen Stellung prophezeiten. Sie kulminierten in der Behauptung, 1950 sei ihre Stellung in der Welt vermutlich stärker als 1938, und dieser Aufwärtstrend werde noch 10 bis 15 Jahre anhalten. ${ }^{97}$ Dabei handelte es sich hier eher um Spekulationen, denn statistisch abgesicherte Einschätzungen fehlten, wie Thierfelder zugeben mußte. ${ }^{98}$ Einige Jahre später, als er eine aktualisierte und erweiterte Ausgabe dieser Forschungen als zweibändiges Werk mit dem Titel „Die deutsche Sprache im Ausland“ herausgab, schob er eine

95 Abgedruckt in: Harvolk, Eichenlaub und Hakenkreuz, S. 143-145.

96 Thierfelder, Deutsche Sprache im Ausland, in: Deutsche Philologie im Aufriß, Bd.1, S. 499-581.

97 Ebenda, S. 543.

98 Ebenda. 
Begründung für seinen sprachpolitischen Optimismus nach. Diese stand nach wie vor in der Tradition anti-westlichen, gegen den angeblichen Materialismus der angelsächsischen Welt gerichteten Denkens der zwanziger Jahre. Zwar mußte man nun die USA als zivilisatorisch und politisch führend anerkennen, verweigerte ihr aber nach wie vor den Ritterschlag zur gleichberechtigten oder zukünftig wegweisenden Kulturnation. ${ }^{99}$ Erneut hieß es bei Thierfelder, die deutsche Sprache habe nicht nur die kriegsbedingten Verluste wettgemacht, sondern trete in vielen Teilen der Welt erstmals als Wettbewerber zumeist mit dem Englischen um die Dominanz auf. Denn nur oberflächlich betrachtet könne man unbestritten von der Weltstellung der englischen Sprache sprechen, nämlich indem man wirtschaftliche und geistesgeschichtliche Zusammenhänge außer acht lasse. Die Dominanz der englischen Sprache rufe zum einen Gegnerschaft hervor, zum anderen habe das Englische „manches Volk überwältigt, aber nicht gewonnen.“ Die englische Sprachstellung sei geistig nicht stark genug unterbaut:

„Millionen, die zum westlichen Lager gehören und den anglo-amerikanischen Völkern durchaus nicht ablehnend gegenüberstehen, fragen sich heute, ob namentlich die Vereinigten Staaten in der Lage sind, im Kleid ihrer Sprache den europäischen und asiatischen Nationen das zu bringen, wonach es diese im Zeitalter der Furcht und Lebensbedrohung so leidenschaftlich verlangt. So mögen viele das Englische als, world language in being', nicht aber als eine Sprache der Zukunft betrachten und ganz gewiß nicht als Sprache epochaler Erfüllung, was ja eigentlich jede Weltsprache sein sollte. ${ }^{\text {100 }}$

Die Ergebnisse seiner Analyse, die er Magnus im Juni 1950 übermittelte, verfehlten zumindest auf diesen nicht den von Thierfelder wohl intendierten Eindruck: Die Förderung der deutschen Sprache sei wieder ein lohnenswertes Tätigkeitsfeld, da die Voraussetzungen, an die man anknüpfen könnte, sich wider Erwarten als ausgesprochen günstig erwiesen. So schrieb Magnus nach Lektüre des Manuskriptes an den Autor: „Jeder, der Ihre Arbeit liest, wird -meine ich - zunächst erstaunt sein, welch großen Umfang die deutsche Sprache heute noch hat. Das ist eine Tatsache von so großer Wichtigkeit, daß eine in geeigneter Form erfolgende Bekanntgabe des Materials mir unbedingt geboten erscheint."101

Die Erfolge, die Werner Günther erzielte, ein ehemaliger Lektor der Deutschen Akademie in Athen, der auf eigene Initiative schon 1951 wieder in der griechischen Hauptstadt Deutschsprachkurse einrichtete, waren zumindest ein ermutigendes Signal dafür, daß die Förderung der deutschen Sprache auch im Schatten der NS-Vergangenheit und selbst in einem Land, das Opfer der deutschen Aggressionspolitik geworden war, kein aussichtsloses Unterfangen sei. Die Idee hingegen, sich auch um die Sprachpflege innerhalb Deutschlands zu bemühen, beim Wiesbadener Arbeitskreis bis zur Jahreswende 1949/50 noch prominent vertreten,

${ }^{99}$ Axel Schildt, Moderne Zeiten. Freizeit, Massenmedien und „Zeitgeist“ der Bundesrepublik der 50er Jahre, Hamburg 1995, S. $404 \mathrm{f}$.

100 Thierfelder, Die deutsche Sprache im Ausland, Bd. 1, S. 56f. Zur Kontinuität in Thierfelders Semantik und Denken zwischen den dreißiger und fünfziger Jahren vgl. jetzt auch Matthias Krell, Franz Thierfelder: „Deutsch als Weltsprache“ oder ein Leben für die Völkerverständigung?, in: Semantischer Umbau der Geisteswissenschaften nach 1933 und 1945, hrsg. von Georg Bollenbeck und Clemens Knobloch, Heidelberg 2001, S. 198-221.

101 BAK B307/118, Brief von Magnus an Thierfelder, 7. 6. 1950. 
wurde im Laufe des Jahres 1950 mit seinen sich eröffnenden außenpolitischen Perspektiven stillschweigend fallengelassen. Dagegen äußerte Thierfelder gegenüber dem Auswärtigen Amt, daß seiner Überzeugung nach Spracharbeit im Ausland "nach wie vor die Grundlage der Auslandsarbeit auf geistigem wie wirtschaftlichem Gebiet überhaupt" sei. ${ }^{102}$

\section{Die Haltung des Auswärtigen Amts}

Die Initiative des Wiesbadener Arbeitskreises zur Gründung einer zentralen, nichtstaatlichen Einrichtung für den Kulturaustausch konnte in der sich konstituierenden Kulturabteilung des Auswärtigen Amts unter Rudolf Salat, der bereits zuvor im Kanzleramt das Referat „Deutsche Kulturbeziehungen zum Ausland“ geleitet hatte, grundsätzlich mit Wohlwollen rechnen. In der offiziell im Mai 1951 wiedererrichteten Kulturabteilung befürwortete man, unterstützt von Diplomaten wie Fritz von Twardowski und Paul Roth, ${ }^{103}$ die im Dritten Reich in der Kulturpolitischen Abteilung gearbeitet hatten, von Anfang an die aus der Weimarer Zeit ererbte Tradition, die Durchführung der Kulturarbeit im Ausland privaten Organisationen zu überlassen. Ja, es wurde bei der Neugründung des Auswärtigen Amts geradezu zum Dogma, daß ein möglichst großer Teil der Kulturbeziehungen zum Ausland über privatrechtlich verfaßte Organisationen abgewickelt werden sollte, um bloß nicht in den Geruch zu kommen, erneut eine staatlich gesteuerte, auftrumpfend auftretende „Propagandapolitik“ wie im Dritten Reich zu betreiben. ${ }^{104}$ Die anfängliche betonte Zurückhaltung des Auswärtigen Amts bei der Initiierung, Koordinierung und auch Finanzierung der auswärtigen Kulturpolitik wurde in einer Antwort der Bundesregierung im Februar 1959 auf eine kleine Anfrage der FDP-Fraktion im Bundestag vom Januar des Jahres 1959 deutlich, in der es hieß:

Die Bundesregierung hat angesichts des Mißbrauchs, der unter dem nationalsozialistischen Regime mit dem verfälschten Begriff einer deutschen Kulturpolitik betrieben worden ist, in

102 PA B90/165 (KA), Schreiben Thierfelders an das Auswärtige Amt, 7. 4. 1951.

103 So verfaßte Paul Roth, der von 1936 bis 1945 in der Kulturpolitischen Abteilung Vortragender Legationsrat gewesen war, im März 1950 eine Denkschrift für die Dienststelle für auswärtige Angelegenheiten im Bundeskanzleramt, also den Kern des späteren "neuen“ Auswärtigen Amts, über „Die frühere Kulturabteilung des Auswärtigen Amts“. In dieser Denkschrift empfahl er eine insgesamt zurückhaltende Vorgehensweise bei der Wiederaufnahme von Kulturbeziehungen zum Ausland, welche unter anderem dadurch erzielt werden könne, daß man diese im wesentlichen privaten Trägern überlasse. Fritz von Twardowski, der letzte Karrierediplomat an der Spitze der Kulturabteilung des „alten“ Amtes, schloß sich in einem Brief vom Mai 1950 dieser Auffassung an. Beide Dokumente befinden sich in: PA B 90/1.

104 In diesem Sinne äußerte sich beispielsweise Salat in einer Aufzeichnung für den Staatssekretär vom 2. 8. 1951, in: PA B90/125 (KA). Im März 1953 wiederholte er diese Gedankengänge gegenüber dem Auswärtigen Ausschuß des Deutschen Bundestages. Vgl. Der Auswärtige Ausschuß des Deutschen Bundestages. Sitzungsprotokolle 1949-1953, bearbeitet von Wolfgang Hölscher, Düsseldorf 1998, 120. Sitzung vom 4. 3.1953 (Dokument 119), S. 1487-1495, hier S. $1493 \mathrm{f}$. 
den ersten Jahren ihrer Tätigkeit Zurückhaltung in ihren Bemühungen um die Pflege kultureller Beziehungen mit dem Ausland geübt und abgewartet, ob vom Ausland her Wünsche nach Wiederaufnahme und Verstärkung kultureller Kontakte an sie herangetragen wurden. So ist z.B. die Initiative zum Abschluß der schon genannten Kulturabkommen durchweg von den Partnerstaaten ausgegangen. Die Bundesregierung glaubt, daß auch in Zukunft die Pflege der Kulturbeziehungen zum Ausland dann am erfolgreichsten sein wird, wenn sie nicht von deutschen Absichten gelenkt wird, sondern den Wünschen und Bedürfnissen der Partnerländer entspricht. " 105

Salat war einer der wenigen Diplomaten des neuen Amtes, der nicht schon in der Wilhelmstraße gearbeitet hatte. Er stand daher vermutlich Neuerungen in der auswärtigen Kulturpolitik aufgeschlossener gegenüber, da er von Traditionen weniger belastet war. Er befürwortete bereits im Mai 1951 grundsätzlich die vom Wiesbadener Arbeitskreis ventilierte Idee einer zentralen, nichtstaatlichen Kulturorganisation. Diese erschien Salat zu diesem Zeitpunkt durchaus realisierbar: Thierfelder, der auf Salat einen sehr guten Eindruck gemacht hatte, war nicht nur spiritus rector des Wiesbadener Arbeitskreises und der Bemühungen um die Wiedergründung der Deutschen Akademie, sondern im Frühjahr 1951 zugleich aussichtsreichster Kandidat für die Stelle des Generalsekretärs des nunmehr in „Institut für Auslandsbeziehungen " umbenannten DAI in Stuttgart. ${ }^{106}$ Das Stuttgarter Institut entschied sich schließlich im Juni 1951 u. a. deshalb für Thierfelder, weil es die beabsichtigte Abkehr von der Förderung des Auslandsdeutschtums, die bis Kriegsende Arbeitsschwerpunkt des Instituts gewesen war, deutlich machen wollte. Die beiden anderen aussichtsreichsten Bewerber um den Posten des Generalsekretärs hingegen waren bislang vor allem in der Deutschtumsarbeit zum Ausland hervorgetreten. ${ }^{107}$ Die Wahl eines Kandidaten, der sich als Generalsekretär der Deutschen Akademie hauptsächlich einen Namen im Kulturaustausch zum Ausland im eigentlichen Sinne gemacht hatte, sollte auch ein Statement gegenüber der amerikanischen Besatzungsmacht sein. Diese hatte zwar das Institut 1945 nicht aufgelöst, blieb aber skeptisch, ob die Einrichtung sich nicht doch wieder der Förderung der deutschen Minderheiten verschreiben würde, die in der NS-Zeit vor allem durch die Auslandsorganisation der NSDAP als fünfte Kolonne des Reichs jenseits der Reichsgrenzen instrumentalisiert worden waren. ${ }^{108}$

Thierfelder selbst gab sich vor seinem Dienstantritt in Stuttgart ebenfalls der Hoffnung hin, das If A mit der wiederzugründenden Deutschen Akademie fusio-

105 Verhandlungen des Deutschen Bundestages. 3. Wahlperiode, Bundestagsdrucksache 798: Kleine Anfrage der FDP betreffend Pflege der kulturellen Beziehungen der Bundesrepublik zum Ausland vom 20. 1. 1959; Verhandlungen des Deutschen Bundestages. 3. Wahlperiode, Bundestagsdrucksache 875: Antwort des Auswärtigen Amts vom 12.2. 1959 (Zitat S. 5).

106 PA B90/165 (KA), Aufzeichnung Salats über das IfA für Staatssekretär Hallstein, 29. 5. 1951, sowie PA B90/125 (KA), Aufzeichnung betreffend IfA und Koordinierung der Auslandsinstitute, 2. 8. 1951.

107 Stadtarchiv Stuttgart Hauptgruppe 6 3007-15, Protokoll der Sitzung des Verwaltungsrates des IfA, 16. 6. 1951.

108 Ebenda, Das Deutsche Auslandsinstitut seit 1945, Aufzeichnung Dr. Isberts vom Januar 1949; Aktennotiz Thierfelders über eine Besprechung mit zwei amerikanischen Beamten, 25. 9. 1951. 
nieren zu können. ${ }^{109}$ Die Idee einer zentralen, nichtstaatlichen Einrichtung zur Organisation des Kulturaustausches mit dem Ausland, auf die Salat im übrigen 1957, inzwischen zum Vatikan versetzt, erneut zurückkam, ${ }^{110}$ ließ sich jedoch nicht realisieren, was Salat sehr bedauerte. ${ }^{111}$ Der Grund lag darin, daß sich die Institutionen auswärtiger Kulturpolitik in der jungen Bundesrepublik dezentral, in den Traditionen ihrer jeweiligen Vorgängerinstitutionen, die in die Weimarer Zeit zurückreichten, wieder konstituierten und, einmal errichtet, auf ihre Unabhängigkeit pochten. So war der DAAD schon im August 1950 wiedergegründet worden. ${ }^{112}$ Bereits nach wenigen Wochen der Tätigkeit in Stuttgart mußte Thierfelder einsehen, daß eine Verschmelzung der geplanten „Allgemeinen deutschen Kulturgesellschaft/Deutsche Akademie“ mit dem IfA nicht möglich sein würde. Die Kräfte in Stuttgart, die für eine unabhängige Fortexistenz des Instituts plädierten, waren zu stark. Den alten Mitarbeitern um den bereits in der Weimarer Republik amtierenden und Ende der vierziger Jahre nochmals aktiv werdenden Vorstandsvorsitzenden und ursprünglichen Begründer des Deutschen Auslandsinstituts, Theodor Wanner, fiel es ohnehin schwer, sich 1950/51 mit der Verlagerung der Institutsarbeit von der Betreuung deutscher Minderheiten im Ausland auf das neue Arbeitsfeld der Kulturbeziehungen zu Ausländern im eigentlichen Sinn abzufinden. ${ }^{113}$ Schon in seinem ersten Arbeitsbericht nach einem halben Jahr Tätigkeit in Stuttgart sprach Thierfelder von einer "Bürde der Tradition“ in Stuttgart, auch wenn er leugnete, daß diese Bürde ihn bei seiner neuen Arbeit drücke. ${ }^{114}$ Etwas deutlicher spielte er in seinem Rechenschaftsbericht über die Tätigkeit des IfA 1951-1956 auf die anfänglichen Schwierigkeiten in Stuttgart an, indem er darauf hinwies, daß die gewandelte Zielsetzung des Instituts auch eine Gesinnungsänderung jener, die im Institut tätig waren, erfordert habe, wobei hier und da "ein Zipfel Volkstumsromantik" wieder an die Oberfläche gekommen sei.115 Vor diesem Hintergrund war es unmöglich, in Stuttgart das Aufgehen des traditionsreichen Instituts in einer neuen Organisation durchsetzen. Auch der neue Vorstandsvorsitzende des Stuttgarter Instituts, Walter Erbe, der zugleich Rektor der Tübinger

109 PA B90/165 (KA), Aufzeichnung über den Besuch Thierfelders im Auswärtigen Amt, 14. 2. 1951.

110 PA B90/155, Ausarbeitung von Botschaftsrat Dr. Salat über die Schaffung einer selbständigen Körperschaft für die deutsche kulturelle Auslandsarbeit, 29. 7. 1957.

111 So schrieb Salat beispielsweise noch am 24.6. 1952 an Thierfelder, er hätte sich gewünscht, daß das IfA und das Goethe-Institut zusammengelegt worden wären, in: PA B90/165 (KA).

112 Vgl. hierzu Peter Alter, Der DAAD seit seiner Wiedergründung 1950, in: Der DAAD in der Zeit. Bd. 1: Der Deutsche Akademische Austauschdienst 1925-2000, hrsg. von Peter Alter, Köln 2000, S. 50-105.

113 So verwies Salat in seiner Aufzeichnung für Hallstein vom 2. 8. 1951 (PA B90/125 (KA)) auf die Vorschläge Wanners über die zukünftige Arbeit des IfA von 1950. Diese hätten im Gegensatz zu den Bonner Vorstellungen in der Tradition des DAI gestanden, da sie auf die Betreuung deutscher Minderheiten im Ausland und die Auswandererberatung abstellten.

114 Arbeitsbericht von Dr. Dr. Franz Thierfelder, in: Mitteilungen. Institut für Auslandsbeziehungen, 1 (1951/52), S. 9-11, hier S. 9.

115 IfA Stuttgart, Tätigkeitsbericht des IfA 1951-1956. 
Universität war, bestand im übrigen auf einer Trennung der kulturpolitischen Aktivitäten in zwei Organisationen, die wie in der Weimarer Republik in München und Stuttgart angesiedelt sein, allerdings eng zusammenarbeiten sollten. ${ }^{116}$

Widerstände gegen eine Fusion gab es aber nicht nur in Stuttgart: Es bestand offenbar nur eine Chance, an das vom bayerischen Staat verwaltete Geld der Deutschen Akademie heranzukommen, wenn eine gesonderte Organisation in München ihre Arbeit aufnehmen würde. ${ }^{117}$ Insofern erwies sich die Tradition der Deutschen Akademie, die von Thierfelder seit 1950 verstärkt beschworen worden war, zwar als in begrenztem Maße finanziell lukrativ, aber im Hinblick auf eine anvisierte organisatorische Neuordnung der deutschen auswärtigen Kulturpolitik als nachteilig. Thierfelder erhoffte sich durch seine Tätigkeit als Generalsekretär in Stuttgart mit gleichzeitigen Sitz im Vorstand des Goethe-Instituts zumindest gewisse Synergieeffekte, schrieb er doch im Februar 1952 an Fehn, der ebenfalls im Vorstand des neu gegründeten Goethe-Instituts saß: „Wir wollen gemeinsam dahin streben, beide Institutionen, bei völliger Unabhängigkeit ihrer Leistung, doch personell so eng wie möglich zu verknüpfen und damit einen Zustand herbeiführen, für den wir ja in der Vergangenheit so viel gearbeitet haben. Es war immer ein Übelstand, daß das Auslandsinstitut und die Deutsche Akademie nie zu wirklich fruchtbarer Zusammenarbeit gekommen sind."118 Er tat sein möglichstes, um von Stuttgart aus den Start des Goethe-Instituts in München als Miniaturausgabe der einstmals ambitionierten Pläne einer „Allgemeinen Deutschen Kulturgesellschaft" zu unterstützen. So gab er durch die Stuttgarter Fonds Hilfestellung bei der Lancierung der ersten Ausgaben der von ihm und Dora Schulz betreuten Zeitschrift „Deutschunterricht für Ausländer" als Nachfolgeorgan von "Deutschunterricht im Ausland“ der Deutschen Akademie, öffnete die neuaufgelegten „Mitteilungen“ des Stuttgarter Instituts zur Berichterstattung über die Arbeitsaufnahme in München und griff dem Goethe-Institut bei der Ausrichtung der ersten Ausländersprachkurse in Bayern im Jahre 1953 finanziell unter die Arme.

\section{Die Gründung des Goethe-Instituts 1951/52}

Parallel zu Thierfelders Bewerbung auf den Stuttgarter Posten und den Überlegungen im Auswärtigen Amt über die Vorteile einer Zentralorganisation für die zukünftige Kulturarbeit zum Ausland zeichnete sich in München jedoch vorerst eine wesentlich bescheidenere Lösung ab. Seit Anfang 1951 wurde deutlich, daß der bayerische Staat zunächst nur einen Teil des Geldes der Deutschen Akademie,

116 BHStA MK Registratur-Spalte II/586/1, Schreiben Erbes an Staatssekretär Brenner im bayerischen Kultusministerium, 6. 9.1951.

117 So bedauerte Thierfelder ebenso wie das Auswärtige Amt die Tatsache, daß das IfA und das Goethe-Institut räumlich wie organisatorisch getrennt blieben, doch anders hätte man kein Geld vom bayerischen Staat aus dem Nachlaß der Deutschen Akademie erhalten können. In: PA B90/165 (KA), Thierfelder an das Auswärtige Amt, 27. 6. 1952.

118 BAK B307/39, Brief Thierfelders an Fehn, 7. 2. 1952. 
nämlich $30000 \mathrm{DM}$, einer ähnlich gearteten Nachfolgeorganisation überlassen wollte, da dies offenbar auch in Bonn gewünscht war. ${ }^{119}$ Auch die Bayerische Akademie der Wissenschaften hatte schließlich nichts mehr dagegen, das finanzielle Erbe der Deutschen Akademie mit der von Thierfelder anvisierten Einrichtung zu teilen, wenn diese sich auf die Aufgaben der früheren praktischen Abteilung beschränken und auf den Namen "Deutsche Akademie" verzichten würde. Salat hatte ebenfalls im Frühjahr 1951 Thierfelder deutlich gemacht, daß er zwar die Einrichtung einer Organisation, welche die Aufgaben der früheren Deutschen Akademie übernehmen würde, begrüße, diese aber nicht den Namen der 1945 aufgelösten Einrichtung tragen solle. ${ }^{120}$

„Da alle an der Arbeit Interessierten sich darüber klar zu werden beginnen, daß der Name ,Deutsche Akademie unnötige Schwierigkeiten heraufbeschwört, so sollte man vielleicht dadurch einen Schritt weiter kommen, daß offen erklärt wird, es solle nur ein, Goethe-Institut zur Fortbildung ausländischer Deutschlehrer' ins Leben gerufen werden. Damit verschwände der Name Deutsche Akademie, aber die Tradition des Goethe-Instituts in München bliebe erhalten. Wenn dadurch die Opposition gewisser Münchener Kreise beseitigt werden könnte, wüßte ich eigentlich nicht, was dann noch an Schwierigkeiten zu überwinden wäre,"

schrieb Thierfelder im April 1951 nach einem Gespräch mit dem Syndikus der Bayerischen Akademie der Wissenschaften an das bayerische Kultusministerium. ${ }^{121}$ Im Juli 1951 beruhigte Thierfelder auch Salat: „Ich betone noch einmal, daß dieser e.V. Deutsche Akademie lediglich eine Hilfskonstruktion sein sollte, der sich in dem Moment auflöst, da die Entscheidung über das Vermögen der Deutschen Akademie endgültig geworden ist. Der Name ,Deutsche Akademie wird keinesfalls wieder aufleben." 122

Abgesehen von den Vorbehalten in Bonn wie München war der 1945 aufgelösten Organisation mit ihrer Bezeichnung als "Deutsche Akademie“ ohnehin nie sehr gedient gewesen, da sie einen pompösen, eher auf wissenschaftliche Arbeit denn auslandskulturpolitische Aktivitäten hinweisenden Beiklang hatte. Zudem war der alte Name in gewisser Weise ja auch schon durch die 1949 in Frankfurt gegründete Deutsche Akademie für Sprache und Dichtung belegt. Die ganzen Bemühungen um die Wiedergründung der Deutschen Akademie seit Anfang 1950 waren also hauptsächlich ein Winkelzug gewesen, um den Staat Bayern zur Herausgabe des Geldes für ein letztlich wesentlich bescheideneres kulturpolitisches Unterfangen zu bewegen. Der wiedergegründete Verein „Deutsche Akademie“, den Thierfelder, Fehn und Magnus im April 1950 in das Münchener Vereinsregi-

119 „Die Bayerische Akademie der Wissenschaften ist ausgeschaltet, die Konten werden umgestellt und die Erklärung des Staatsrats Dr. Meinzolt liegt vor, daß mit dem Geld die Hauptstelle der Deutschen Akademie finanziert werden soll“, schrieb Thierfelder am 8. 1. 1951 an die Sekretärin von Magnus, in: BAK B307/118. Im April 1951 wird erstmals der Zuschuß in Höhe von 30000 DM aus der Hinterlassenschaft der Deutschen Akademie in einem Schreiben Thierfelders an das Auswärtige Amt erwähnt, in: PA B90/165 (KA).

120 BHStA MK Registratur-Spalte V/1275, Aufzeichnung über die Besprechung zwischen Staatsrat Meinzolt und Thierfelder, 5. 3. 1951.

121 BHStA MK Registratur-Spalte II/586/I, Schreiben Thierfelders an Meinzolt, 20. 4. 1951.

122 PA B90/125 (KA), Schreiben Thierfelders an Salat, 13. 7. 1951. 
ster hatten eintragen lassen, führte folglich auch, wie Thierfelder Salat zugesagt hatte, nur ein Schattendasein auf dem Papier, bis er im September 1962 erneut und diesmal endgültig aus dem Vereinsregister gelöscht wurde.

Die seit Frühjahr 1951 sich abzeichnende Gründung eines Kulturinstituts in München war eine Art Balanceakt: Einerseits sollte eine Organisation gegründet werden, die zumindest Teile der Tätigkeit der 1945 aufgelösten Vorgängerorganisation weiterführen würde, welche auf dem Feld der auswärtigen Kulturpolitik seit 1945 brachlagen und die nicht zuletzt bearbeitet werden sollten, um an das vom bayerischen Staat verwaltete Geld heranzukommen. Andererseits durften im In- wie Ausland keine Vorbehalte wegen der Wiederbelebung der historisch vorbelasteten Vorgängerinstitution hervorgerufen werden. Ein klar umrissenes, wesentlich eingegrenzteres Tätigkeitsfeld als jenes der alten Akademie oder einer "Allgemeinen Deutschen Kulturgesellschaft" empfahl sich seit 1950 auch, um nicht an den kulturpolitischen Empfindlichkeiten und Kompetenzen der Bundesländer und der bereits bestehenden Einrichtungen wie dem IfA, dem DAAD oder der Bayerischen Akademie der Wissenschaften zu rühren. So bot sich der Name der 1932 gegründeten Abteilung "Goethe-Institut zur Förderung ausländischer Deutschlehrer" der vormaligen Akademie zunächst als Kompromiß an, mit dem alle leben konnten. „Unsere ursprünglichen umfangreichen Pläne sind auf ein bescheidenes Maß zurückgeführt worden. In diesem bescheidenen Maße sind sie aber ausführbar," schrieb denn auch Magnus am 2. August 1951 an den Rechtsanwalt Karl Ferdinand Reuss in München und bat ihn, eine Satzung für den zu gründenden Verein auszuarbeiten. ${ }^{123}$ Eine Woche später, am 9. August 1951, kam es in einer unspektakulären Zusammenkunft in der Münchener Tengstraße im Hause des Verlegers Wolfgang Müller-Clemm zur Gründung des Vereins "Goethe-Institut zur Förderung ausländischer Deutschlehrer“. Anwesend waren neben Müller-Clemm und Rechtsanwalt Reuss Thierfelder, Fehn, Magnus, sowie die Ex-Lektoren Dora Schulz und Hubert Strecker sowie das Ehepaar Rederer, beide ehemalige Akademiemitarbeiter in der Münchener Geschäftsstelle.124

Außer der Herausgabe der Zeitschrift „Deutschunterricht für Ausländer“, deren Redaktion Thierfelder und Schulz seit Herbst 1951 übernahmen, erfolgte aber nach der Zusammenkunft vom 9. August beinahe ein Jahr lang nichts. Erst Ende April 1952 wurde der neue Verein in das Münchener Vereinsregister eingetragen, allerdings mit dem veränderten Zusatz „zur Pflege der deutschen Sprache im Ausland“. Diese Namensänderung rührte daher, daß der Germanist Werner Richter, Professor an der Bonner Universität, der vom Auswärtigen Amt zu einer Besprechung über das Goethe-Institut hinzugezogen worden war, sich an der Namensbezeichnung des neuen Vereins stieß: Es sei Aufgabe der Universitäten, Lehrer aus- und fortzubilden. ${ }^{125}$ Außerdem wurde im Frühjahr 1952 deutlich, daß man vom bayerischen Staat nur eine einmalige Zahlung von 30000 DM sowie Mobiliar und die Bibliothek aus der Erbmasse der Deutschen Akademie erhalten würde. Die 30000 DM waren also nicht, wie ursprünglich von den Vereinsgründern er-

123 Goethe-Institut München, Stammakte.

124 Ebenda, Niederschrift über die Gründungssitzung am 9. 8. 1951.

125 PA B90/165 (KA), Protokoll der Besprechung im Auswärtigen Amt, 19. 10. 1951. 
hofft, ${ }^{126}$ nur eine Abschlagszahlung bis zur Übertragung des gesamten Restguthabens gewesen. Folglich brauchten die Gründer sich auch nicht mehr sklavisch an den Namen der einstigen Unterabteilung der Deutschen Akademie zu halten, damit der neue Münchener Verein wie ein Rechtsnachfolger erschien. Schließlich war der ursprüngliche Name ohnehin für die beabsichtigte Tätigkeit des neuen Vereins zu restriktiv gewesen: Die Gründer wollten von Anfang an nicht nur ausländische Deutschlehrer in München fortbilden, sondern in der Tradition der Deutschen Akademie auch Sprachkurse im Ausland abhalten.

In einer Denkschrift Thierfelders über Aufgaben und Arbeitsprogramm des Goethe-Instituts vom 20. August 1951 hieß es entsprechend der von ihm bereits Ende der zwanziger Jahre entwickelten Argumentation:

„Die Pflege und Förderung der deutschen Sprache im Ausland ist Kernstück deutscher Kultur- und Exportpolitik. Unsere geistige und wirtschaftliche Stellung in Europa hat in der Vergangenheit ganz wesentlich darauf beruht, daß Deutsch die meistgesprochene Sprache des Kontinents war. Die Entwicklung des Überseehandels folgte oder ging der Sprachausbreitung in anderen Erdteilen voraus [...] Deutschland in seiner politischen Machtlosigkeit und inneren Spaltung besitzt in der Sprache das stärkste Instrument zu einer allgemeinen Besserung seiner Lage in der Welt. Deshalb kann die Wiedererrichtung des Goethe-Instituts, das in den letzten 20 Jahren Wesentliches zur Festigung unserer Sprachgeltung im Ausland beigetragen hat, zu einer neuen Wendung unserer Nachkriegsentwicklung beitragen."

Als erste Aufgabe nannte die Aufzeichnung die Einrichtung von Kursen zur Erlernung des Deutschen dort, wo ein natürliches Bedürfnis bestehe, erst die folgenden Punkte forderten als künftige Tätigkeit des Vereins auch die Ausbildung von Deutschlehrern und die Erarbeitung von Unterrichtsmaterialien. Schließlich sollte das neue Institut sich auch um die Förderung des fremdsprachlichen Unterrichts in Deutschland bemühen und eine Sprachstatistik über die Fremdsprachen in der Welt führen. ${ }^{127}$ Die Idee, der neue Verein solle sich auch der Förderung fremder Sprachen in Deutschland verschreiben, die allerdings nie realisiert wurde, war Ausdruck von Thierfelders bereits in den zwanziger Jahren in Ansätzen vorhandenen Überzeugung, ${ }^{128}$ daß jede Kulturarbeit im Ausland auf Gegenseitigkeit beruhen solle: So wie die Förderung der deutschen Sprache im Ausland nicht zuletzt zur Verständigung der Völker beitragen solle, müsse in diesem Sinne auch den fremden Sprachen in Deutschland das Tor geöffnet werden. „Deutsche Sprachpflege im Ausland, die nicht gleichzeitig ihr Augenmerk auf die Förderung der Fremdsprachen im Inland richtet, erfüllt ihre Aufgabe nicht vollständig“, hieß es in einer weiteren Denkschrift Thierfelders über die Arbeit des Goethe-Instituts vom Oktober 1951, die er für das Auswärtige Amt anfertigte. ${ }^{129}$

126 Ebenda, Brief Thierfelders an das Auswärtige Amt, 13. 7. 1951.

127 BAK B307/110, Das Goethe-Institut zur Förderung ausländischer Deutschlehrer: Aufgaben und Arbeitsprogramm, Aufzeichnung Thierfelders vom 20. 8. 1951.

$128 \mathrm{Vgl}$. hierzu beispielsweise Thierfelders Vortrag auf der Hauptversammlung der Deutschen Akademie in Jena im Oktober 1929 über "Deutsche Spracharbeit im Ausland“ (siehe Kapitel 3), in dem er allerdings das Prinzip der Gegenseitigkeit vor allem aus Gründen der Effizienz der eigenen Kulturwerbung befürwortete.

129 PA B90/165 (KA), Die Organisation der Arbeit des Goethe-Instituts, Denkschrift Thicrfelders vom 19. 10. 1951. 
Der Hinweis auf die enge Verbindung von Sprachverbreitung und Exportchancen war vor allem als Köder für potentielle Förderer aus der Wirtschaft gedacht. Die Gründer des neuen Goethe-Instituts erhofften sich ursprünglich, dieses nach einer Starthilfe vom bayerischen Staat und dem Auswärtigen Amt hauptsächlich aus Privatspenden finanzieren und damit weitgehend von staatlicher Einflußnahme freihalten zu können, so wie auch die Deutsche Akademie bis Kriegsausbruch einen Großteil ihres Budgets ebenfalls durch Spenden von privater Seite bestritten hatte. ${ }^{130}$ Diese Erwartung war insofern erstaunlich, als gerade Thierfelder doch sehr wohl wußte, wie prekär die Finanzsituation der Deutschen Akademie in den zwanziger und dreißiger Jahren stets gewesen war, als sie sich zum Großteil auf Spenden hatte verlassen müssen. Doch vermutlich erschien ihm diese finanzielle Schwäche als geringeres Übel verglichen mit der Gefahr, daß der neue Verein womöglich eines Tages wegen seiner Abhängigkeit von öffentlichen Geldern von staatlicher Seite instrumentalisiert oder erpreßbar gemacht oder seine Arbeit dadurch im Ausland in Mißkredit gebracht werden könnte. Um deutsche Unternehmen als Sponsoren für die Sprachwerbung zu gewinnen, bemühte man erneut die Geschichte der Deutschen Akademie, wiederum in einer den Erfordernissen der Zeit angepaßten Version: In einem Rundbrief an deutsche Unternehmen vom Februar 1953 wurde auf die guten Beziehungen zwischen Goethe-Institut und deutscher Wirtschaft in den Jahren 1932 bis 1945 hingewiesen, die es dem Goethe-Institut ermöglicht hätten, vor dem Kriege rund 300 (!) Lektorate größtenteils aus Mitteln der Wirtschaft zu unterhalten. ${ }^{131}$ Die Hoffnung auf ein großzügiges Sponsoring der Kulturarbeit durch die Wirtschaft erfüllte sich nicht, wie schon 1953/54 deutlich wurde:132 Die Produkte der deutschen Unternehmen verkauften sich in den fünfziger Jahren im Ausland ungeachtet der Stellung der deutschen Sprache wegen der allgemein günstigen Konjunktur der Weltwirtschaft, dem Abbau von Handelshemmnissen, der relativ niedrigen Löhne in der Bundesrepublik und einer unterbewerteten Mark jenseits der Grenzen besser als jemals in der Zwischenkriegszeit. Im übrigen stellte sich heraus, daß die Nachfrage nach Deutschkursen nicht unbedingt dort am größten war, wo die stärksten Abnehmer deutscher Produkte saßen: Während das frühe Goethe-Institut anfangs vor allem Auslandsdozenturen im Nahen und Mittleren Osten einrichtete, wurde ein Großteil des Außenhandels der Bundesrepublik mit Westeuropa abgewickelt. ${ }^{133}$

130 In diesem Sinne äußerte sich beispielsweise Magnus in einem Schreiben an das Auswärtige Amt vom 16. 2. 1952: Das Goethe-Institut brauche lediglich eine Anschubfinanzierung vom Auswärtigen Amt, danach bestehe die berechtigte Hoffnung, daß es sich wie einstmals die Deutsche Akademie durch die Wirtschaft finanzieren werde, in: PA B90/ 165 (KA).

131 PA B 90/167 (KA), Vertrauliches Anschreiben „An die Wirtschaftsgruppe ...“, 22. 2. 1953. Tatsächlich waren es ja nie mehr als 50 Lektorate vor Kriegsausbruch gewesen.

$132 \mathrm{Vgl}$. die entsprechenden Hinweise in den Vorstandssitzungen des Vereins 1953/54, in: BAK B307/25.

133 Vgl. hierzu überblicksartig Gerd Hardach, Die Rückkehr zum Weltmarkt 1948-1958, in: Modernisierung im Wiederaufbau. Die westdeutsche Gesellschaft der 50er Jahre, hrsg. von Axel Schildt und Arnold Sywotteck, Bonn 21998, S. 80-104. 
Am 30. Juni 1952 kam es zur ersten Vorstandssitzung des neuen Goethe-Instituts, auf welcher der Geist der Deutschen Akademie für den neuen Verein beschworen wurde, der den Namen der Vorgängerinstitution aus historischen Gründen nicht tragen sollte: Magnus als Vereinsvorsitzender erklärte, Grundlage für die aufzunehmende Arbeit sei die Deutsche Akademie, in der sich hervorragende Persönlichkeiten des geistigen Deutschlands getroffen hätten. Sie sei im Ansehen mit der Académie Française vergleichbar gewesen und die Zugehörigkeit zu ihr sei einem Ritterschlag gleichgekommen. „Die Tätigkeit des Goethe-Instituts soll sich in ihren Leistungen würdig an die Tradition der Deutschen Akademie anschließen, und sie nicht nur in Form und Brauchtum übernehmen." Thierfelder versprach, das Goethe-Institut werde politisch genauso neutral sein wie die Deutsche Akademie vor 1936. Ein verkappter Nationalismus habe im neuen Verein nichts zu suchen, vielmehr eröffne die Tätigkeit des Instituts der Stadt München die Gelegenheit, Weltläufigkeit zurückzugewinnen. ${ }^{134}$

\section{Ausblick: Arbeitsaufnahme 1952-1959/60}

Am 1. Juli 1952 nahm die Geschäftsstelle des Vereins die Arbeit in der HerzogRudolf-Straße 7 in München auf. Geleitet wurde sie von Helmuth Brückmann. Ihm assistierten zwei Halbtagssekretärinnen, die schon für die Deutsche Akademie aktiv gewesen waren. Brückmann, Major a.D. der Luftwaffe und als Sohn eines Engländers zweisprachig aufgewachsen, war studierter Germanist. Er hatte zeitweilig eine private Dolmetscherschule in München geleitet, die zuvor die Räume in der Herzog-Rudolf-Straße genutzt hatte. Obwohl ohne Akademie-Vergangenheit, war er ein Protegé Thierfelders. Brückmann hatte bereits im Wiesbadener Arbeitskreis die allerdings mehr auf dem Papier existente „Arbeitsstelle für Fremdsprachen und geistigen Austausch“ geleitet und blieb bis 1958 Geschäftsführer, als ihn der Akademie-Veteran Richard Wolf ablöste, der zuletzt Mittelstellenleiter im besetzten Belgrad gewesen war. Thierfelder wollte Brückmann zu seinem Nachfolger aufbauen, der eines Tages die gleiche Rolle spielen sollte, die er selbst in der Deutschen Akademie eingenommen hatte. ${ }^{135}$ Denn Thierfelder, dies war absehbar, mußte sich aufgrund seiner Verpflichtungen in Stuttgart mittelfristig aus den Geschäften des Münchener Vereins zurückziehen. ${ }^{136}$ Dies geschah bis 1959 schrittweise, als er schließlich aus dem Pädagogischen Beirat des Goethe-Instituts ausschied, nachdem er schon 1956 seinen Sitz im Vorstand niedergelegt hatte.

Als erstes organisierte die Geschäftsstelle des neuen Goethe-Instituts im Oktober 1952 ein Auswahlseminar für künftig zu entsendende Auslandsdozenten in Seeshaupt am Starnberger See. Die Wiederaufnahme der Arbeit der Deutschen

134 BAK B307/24, Niederschrift über die Vorstandssitzung des Goethe-Instituts, 30. 6. 1952.

135 So Thierfelder in einem Schreiben an Salat vom 7. 4. 1952, in: PA B90/165 (KA).

136 So schrieb er bereits im Februar 1952 an Fehn, er wolle sich, wenn das Goethe-Institut seine Tätigkeit einmal aufgenommen habe, vor allem auf die Arbeit in Stuttgart konzentrieren, in: BAK B307/39. 
Akademie durch das Goethe-Institut in den fünfziger Jahren sollte nicht ausschließlich durch Verwendung des früheren Personals erfolgen. Abgesehen davon, daß die Mehrzahl der ehemaligen Akademiemitarbeiter Anfang der fünfziger Jahre schon an anderer Stelle wieder Verwendung gefunden hatte - im Falle der ehemaligen Lektoren zumeist im Schuldienst - und ein bloßes Wiedereinstellen früherer Kräfte rasch zu einer Überalterung des Mitarbeiterstabes geführt hätte, war dies auch eine politische Entscheidung. Zwar waren bewährte Kräfte der Vorläuferorganisation wie Schulz, Wolf, Günther und Graf von Posadowsky in Athen als Lektoren oder Sekretärinnen für die Arbeit in der Zentrale wie in den Außenstellen willkommen. Doch ebenso achtete vor allem Thierfelder, der die Entwicklung der Akademie seit 1937 als eine Art Verrat an seinen Idealen und Unterminierung der von ihm geleisteten Aufbauarbeit aufgefaßt hatte, darauf, daß nur solche Akademieveteranen Verwendung fanden, die sich im Dritten Reich nicht zu sehr exponiert hatten. Bereits in seiner Aufzeichnung vom August 1945 über die „Politische Tätigkeit der Deutschen Akademie“ hatte er eine genaue Überprüfung des Akademiepersonals gefordert. Folglich fand keine der führenden Kräfte, die in der Geschäftsstelle der Akademie in München oder im alten Goethe-Institut vor und im Kriege gearbeitet hatte, in der Nachfolgeorganisation Anstellung, ebensowenig Lektoren, die der NSDAP angehört oder mit deren Auslandsorganisation zusammengearbeitet hatten. ${ }^{137}$ Das frühe Goethe-Institut war also einerseits eine Institution, die starke inhaltliche wie personelle Kontinuitäten zur Arbeit der Vorgängerinstitution im Dritten Reich aufwies und sich durchaus in der Tradition der damals geleisteten Arbeit sah. Andererseits aber, was recht ungewöhnlich für damalige bundesdeutsche Einrichtungen war - man denke nur an das Auswärtige Amt, in dem zwei Drittel der führenden Positionen 1952 von ehemaligen Parteigenossen besetzt waren ${ }^{138}$-, blieb es frei von überzeugten früheren Nationalsozialisten und selbst nominellen Parteigenossen.

Auf dem ersten Auswahlseminar in Seeshaupt machte Thierfelder den Bewerbern in zwei Vorträgen über „Deutsche Sprache im Ausland“ und „Umgang mit Völkern" die Grundsätze deutlich, die er schon seit den zwanziger Jahren zu Richtlinien auswärtiger Kulturpolitik erkoren hatte: Es dürfe keine Vermengung von Kulturarbeit und Politik geben, das Fundament der auswärtigen Kulturpolitik sei die Sprache, der Verzicht auf die Muttersprache hingegen bedeute den Verlust der Volkszugehörigkeit, ihre Pflege und Verbreitung sei „natürliche Pflicht und ein gesundes Bestreben“, das die "Verminderung des Fremden" in der Welt

137 So forderte Thierfelder in der Vorstandssitzung vom 10.2. 1954, die ins Ausland zu entsendenden Dozenten seien darauf zu überprüfen, ob sie in der Auslandsarbeit der NSDAP hervorgetreten seien. Falls dies der Fall gewesen sei, müßten sie auf jeden Fall abgelehnt werden, in: BAK B307/24.

$138 \mathrm{Vgl}$. Döscher, Verschworene Gesellschaft, S. 311. Paradoxerweise war gerade die Kulturabteilung des wiedergegründeten Amtes in der Anfangsphase relativ frei von alten Parteigenossen und eine „katholische“ Hochburg in einem ansonsten protestantisch geprägten Amt (S. 121). Dieser Umstand rührte wohl nicht zuletzt daher, daß die Diplomaten, die schon in der Wilhelmstraße gedient hatten, die Kulturabteilung ohnehin nie als karriereträchtiges Sprungbrett angesehen hatten und sie daher getrost Außenseitern wie Salat überlassen konnten. 
zum Ziel habe. Verbreitung der eigenen Sprache und Erlernen fremder Sprachen seien kein Gegensatz, und keine Sprache sei so unbedeutend, daß sie es nicht Wert sei, erlernt oder verbreitet zu werden. Die deutsche Sprache habe, wenn auch „blutend“, die Niederlage überstanden und rücke wieder in ihre alte Stellung ein, wobei Deutsch, Französisch und Englisch die wichtigsten Weltsprachen seien, da „es heute keine Sprache mit uneingeschränkter Weltgeltung mehr gibt“. Deutsch, so behauptete Thierfelder ohne nähere Begründung, sei vielmehr „Nutznießer der gegenwärtigen Weltsituation“. Auch ein weiteres Standardthema Thierfelders fehlte nicht: Der nötige Takt im Umgang mit fremden Völkern bei der Kulturarbeit, der gerade den Deutschen schwerfiele, da sie kompromißfeindlich, wahrheitsfanatisch, schulmeisterlich, arbeitswütig und von einer gewissen „Formlosigkeit“ seien. Auch in anderer Hinsicht wurde an frühere Zeiten angeknüpft: Lehrer Lapper gab auf diesem Seminar eine Kostprobe seiner Methode des „singenden Lernens" und behauptete, mit dieser würden Ausländer innerhalb von sechs Wochen fließend deutsch sprechen und Universitätsvorlesungen folgen können. ${ }^{139}$ So war es nicht erstaunlich, daß im Mai 1953 die erste Unterrichtsstätte für ausländische Sprachschüler des Goethe-Instituts in Bad Reichenhall eröffnete, denn Lapper, der in der Nähe wohnte, sollte die Kurse leiten. ${ }^{140}$ Allerdings stellte sich schon nach einigen Tagen des Unterrichts in Bad Reichenhall nach der Methode Lappers heraus, daß der Vermittlung des Deutschen durch tägliches, stundenlanges Absingen der Melodie von „Morgen kommt der Weihnachtsmann“ selbst bei variierendem Text und steigender grammatikalischer Komplexität der Verszeilen Grenzen gesetzt waren, ja die Methode durchaus Widerstand bei den Kursteilnehmern hervorrief. Lapper wurde nach ein paar Wochen von seiner Lehrtätigkeit entbunden, ${ }^{141}$ was das Ende der seit den dreißiger Jahren bestehenden Kooperation zwischen ihm und dem Goethe-Institut bedeutete.

Es gab noch eine zweite, etwas länger anhaltende Kontinuität zwischen dem Deutschunterricht der Deutschen Akademie und jenem des frühen Goethe-Instituts: Zunächst nutzte man für den Unterricht eine politisch aktualisierte Auflage des Buches „Gesprochenes Deutsch“. München als „Hauptstadt der Bewegung“, Wien als „Hauptstadt der Ostmark", der Reichsarbeitsdienst und einige andere Hinweise, die auf die Entstehung der ursprünglichen Fassung im Dritten Reich hingewiesen hatten, waren aus der Neuauflage von 1953 getilgt worden. Das neue Goethe-Institut brachte allerdings 1955 ein eigenes Lehrwerk, von Dora Schulz und Heinz Griesbach erarbeitet, unter dem Titel „Deutsche Sprachlehre für Ausländer" heraus, das „Gesprochenes Deutsch“ fortan ersetzte.

Die Unterrichtsstätten im Inland waren eine Neuerung im Vergleich zur alten Akademie, die sich auf die Fortbildung ausländischer Deutschlehrer in München beschränkte, hingegen im Inland keine Anfängerkurse angeboten hatte. Sie gingen auf eine Initiative Brückmanns zurück, der in ihnen eine Chance witterte, dem

139 PA B90/166 (KA), Bericht über den ersten Vorbereitungskurs für zukünftige Lektoren und Sprachlehrer im Ausland, Aufzeichnung von Brückmann von Ende Oktober 1952.

140 Helmuth Brückmann, Anfang und Aufbau. Die Jahre 1952 bis 1958, unveröffentlichtes Manuskript im Goethe-Institut München, S. 14.

141 Vgl. hierzu Griesbach, Am Anfang war fast nichts, S. 73 f. 
jungen Verein eine Einnahmequelle zu verschaffen. ${ }^{142}$ Die Unterrichtstätten - auf Bad Reichenhall folgten 1954 Murnau und ein Jahr später Kochel und Burg - erwiesen sich tatsächlich als erfolgreiche Einrichtungen, die nicht nur sich selbst trugen, sondern sogar einen bescheidenen Gewinn abwarfen. Ihre Zahl vermehrte sich folglich bis Ende der fünfziger Jahre auf zwölf. Alle waren in Kleinstädten angesiedelt, denn hier waren die Unterbringungskosten geringer und die Sprachschüler konnten sich ganz auf das Lernen konzentrieren, da es wenig Ablenkung gab. Die Unterrichtsstätten zogen vor allem Sprachschüler aus dem Nahen und Mittleren Osten und Nordafrika an, in den ersten vier Jahren beinahe doppelt so viele wie aus dem europäischen Ausland. Die Sprachschüler aus den außereuropäischen Ländern nutzten die Intensivsprachkurse vor allem, um sich auf ein Studium in Deutschland vorzubereiten. ${ }^{143}$

Zudem übernahm der Verein 1953 die seit 1951 von dem ehemaligen Akademielektor Günther in Athen auf eigene Initiative organisierten Deutschsprachkurse als ersten Auslandsstützpunkt des Goethe-Instituts. Im Gegensatz zu den Unterrichtsstätten im Inland erwiesen sich die Auslandsdozenturen aber als so kostspielig, daß sie, wie sich bald herausstellte, nur durch staatliche Subventionen zu unterhalten waren. Sie waren u.a. so teuer, da man im Zeichen des Wirtschaftswunders der neuen Generation von Goethe-Dozenten im Ausland materiell mehr bieten mußte als den Akademielektoren der dreißiger und vierziger Jahre, wie sich Thierfelder in einer Vorstandssitzung des Vereins beklagte. ${ }^{144}$ Trotzdem stieg die Zahl der Auslandsdozenturen bis zum Ende des Jahrzehnts auf 18 mit 62 entsandten Kräften, da das Auswärtige Amt dem Münchener Institut immer mehr Geld zuschoß: Aus dem ursprünglich anvisierten Zuschuß aus Bonn von etwa 70000 DM, den Thierfelder und Magnus 1951/52 in ihrem Glauben, den neuen Verein vornehmlich aus privaten Spenden finanzieren zu können, zunächst für ausreichend gehalten hatten, waren Ende der fünfziger Jahre etwa 1,6 Millionen DM an jährlichen Subventionen des Auswärtigen Amts geworden, die ca. $60-70 \%$ des Gesamtbudgets des Goethe-Instituts ausmachten. Zwischenzeitlich, im Sommer 1955, war die finanzielle Situation des Vereins so kritisch gewesen, daß man eine Verlegung der Tätigkeit nach Stuttgart erwog, da die baden-württembergische Landeshauptstadt einen wesentlich höheren jährlichen Zuschuß als München sowie die Bereitstellung kostenloser Büroräume in Aussicht gestellt hatte. Wieder war es die Tradition der Deutschen Akademie, die Einfluß auf die Geschicke des Goethe-Instituts nahm: Thierfelder sprach sich unter Hinweis auf die seit den

142 Brückmann, Anfang und Ausbau, S. 14.

143 Bis zum 31.3. 1957 stammten von den insgesamt 3625 Sprachschülern, die seit 1953 die Unterrichtsstätten im Inland besucht hatten, 1914 aus diesen Regionen, insbesondere aus Ägypten, Jordanien, Libanon, Syrien, Türkei, Iran, Irak und Indien. Lediglich 1110 stammten aus dem europäischen Ausland. Vgl. 5 Jahre Goethe-Institut München 19521957, hrsg. vom Goethe-Institut, München 1957, S. 10.

144 BAK B307/25, Protokoll der kombinierten Sitzung des Vorstands und Verwaltungsrats vom 21. 3. 1955. 
dreißiger Jahren von München erfolgreich geleistete Spracharbeit gegen eine Übersiedlung nach Stuttgart aus. ${ }^{145}$

Die Gründung der Akademielektorate in den dreißiger Jahren war auf Anregung Thierfelders und in Absprache mit dem Auswärtigen Amt einem klaren Plan gefolgt: Sprachpolitisch wollte man in den Ländern Jugoslawien, Griechenland und Bulgarien einen Umschwung zugunsten des Deutschen herbeiführen als Beitrag zur Balkanstrategie des Reiches, das dort ein „informal empire“ errichten und daher vor allem den französischen Einfluß in diesem Großraum zurückdrängen wollte. Die Einrichtung der Goethe-Dozenturen in den fünfziger Jahren hingegen basierte auf keinem Plan, der einer klaren außenpolitischen Intention folgte. Man projektierte und eröffnete Dozenturen einfach dort, wo der Münchener Verein ein allgemeines Interesse für deutsche Sprache und Kultur vermutete, ${ }^{146} \mathrm{da}$ man in München wie Bonn offenbar froh war, daß sich dieses nach den Ereignissen der Jahre 1933 bis 1945 überhaupt erhalten hatte. Zudem mußte der Verein, wollte er, so wie es sich die Gründer noch in der Anfangsphase erhofften, von staatlicher Zuwendung möglichst frei bleiben, vor allem nachfrageorientiert handeln. Auch das Auswärtige Amt schien keine eindeutigen Schwerpunkte in geographischer Hinsicht benennen zu wollen. Es wurde 1955 nur recht allgemein vereinbart, daß man sich bei der Eröffnung neuer Dozenturen auf den Nahen, Mittleren und Fernen Osten konzentrieren solle, da sich dort derzeit besonders gute Entwicklungsmöglichkeiten für die deutschen Interessen ergäben. ${ }^{147}$ Entsprechend weit gestreut lagen die Dozenturen 1959: Drei befanden sich in Griechenland sowie jeweils eine in Spanien, Italien, Finnland, Frankreich, Türkei, Libanon, Syrien, Ägypten, Sudan, Liberia, Irak, Indien, Malaysia, Thailand und Japan.

Seit Sommer 1959 zeichnete sich ein neuer Abschnitt in der Geschichte des Münchner Vereins ab, der ihn aus dem Schatten der reinen Sprachförderung und damit auch aus jenem der Deutschen Akademie herausführen sollte. Der neue Leiter der Kulturabteilung des Auswärtigen Amts, Dieter Sattler ${ }^{148}$, der im Juli 1959 sein Amt antrat, vereinbarte mit dem Münchener Verein, daß dieser ab 1960 schrittweise alle deutschen Kulturinstitute im Ausland übernehmen solle. Sattler war zuvor Kulturreferent an der Botschaft in Rom (Quirinal) gewesen und hatte hier u. a. Gelegenheit gehabt, mit Salat, der von 1954 bis 1957 als Referent an der Botschaft im Vatikan arbeitete, die strukturellen Probleme der deutschen auswärtigen Kulturpolitik seit der Wiedergründung des Auswärtigen Amts zu erörtern. Beide waren sich darin einig, daß diese einer stärkeren organisatorischen Zusammenfassung bedürfe, idealerweise durch Gründung einer Art „German Council“ nach britischem Vorbild. Sattlers Berufung war eine Reaktion von Außenminister

145 Ebenda, Protokoll der kombinierten Sitzung des Vorstands und Verwaltungsrats vom 1.7. 1955.

146 Diese Planlosigkeit wurde bereits in der Anfangsphase des Goethe-Instituts von einem Vertreter des Auswärtigen Amts, der im Herbst 1953 einer Vorstandssitzung des GoetheInstituts beiwohnte, gegenüber der Kulturabteilung moniert. Vgl. PA B90/170 (KA), Bericht über die Sitzung des Verwaltungsrats und des Vorstands des Goethe-Instituts vom 26. 10. 1953, 31. 10. 1953.

147 BAK B307/159, Protokoll der Besprechung im Auswärtigen Amt, 20. 6. 1955.

148 Grundlegend hierzu Stoll, Kulturpolitik als Beruf. 
Heinrich von Brentano auf die in der Öffentlichkeit aufgekommene Kritik an den Leistungen des Amts in der kulturellen Selbstdarstellung der Bundesrepublik im Ausland.

Bereits bei einem Treffen der Kulturreferenten der westdeutschen Botschaften Anfang 1956 in Bonn hatten diese übereinstimmend festgestellt, daß in allen Ländern eine verstärkte kulturpolitische Aktivität des Ostblocks zu verzeichnen sei, die keine zufällige Häufung von Einzelinitiativen sein könne. ${ }^{149}$ Der Kampf der Systeme hatte sich also in den Augen der Kulturfunktionäre nach der 1955 abgeschlossenen Konsolidierung der Machtblöcke und dem politischen und militärischen Patt zwischen beiden Lagern auf die Ebene der Kulturpolitik verlagert. Dies war eine Interpretation, die nicht zuletzt geeignet war, mehr Geld für die auswärtige Kulturpolitik fordern zu können. Die öffentliche Debatte war 1957 angestoBen worden, als der nordrhein-westfälische Kultusminister Paul Luchtenberg die Errichtung eines „Senats für kulturelle Auslandsarbeit" gefordert hatte, und seitdem nicht mehr verstummt. Prominente Stimmen in dieser Diskussion waren u.a. Bundestagspräsident Eugen Gerstenmaier, der ehemaliger Ministerpräsident Schleswig-Holsteins und Vorsitzende der deutschen UNESCO-Kommission und der Gesellschaft für Auswärtige Politik, Theodor Steltzer, sowie der Schriftsteller und Journalist Bruno E. Werner, der seit 1952 zugleich Kulturattaché an der Botschaft in Washington war. ${ }^{150}$ Die geäußerte Kritik war auch Ausdruck wachsender Befürchtungen in der Bundesrepublik, daß es der DDR, der man große Mittel zur Durchführung ihrer auswärtigen Kulturpolitik zuschrieb, 151 im Rahmen der dem Osten unterstellten kulturpolitischen Offensive gelingen könnte, sozusagen als ersten Schritt einer späteren diplomatischen Anerkennung kulturpolitisch in den jungen Nationen des Nahen und Mittleren Ostens Fuß zu fassen. Um in den neuentstandenen Staaten (west-)deutsche Interessen wirkungsvoll zu vertreten, mußte sich Bonns auswärtige Kulturpolitik im Grunde genommen von einer bloßen Selbstdarstellung zu einer Art kultureller Entwicklungspolitik wandeln, die dem Gaststaat helfen würde, seine Kultur zu bewahren, zu entwickeln und über die eigenen Grenzen hinaus bekannt zu machen. Diese Überlegungen wurden ansatzweise schon 1958 von Gerstenmaier geäußert, fanden ihren Durchbruch aber erst ein Jahrzehnt später. ${ }^{152}$ Die Diskussionen um die deutsche auswärtige Kulturpolitik gipfelten ganz im Sinne Salats und Sattlers in der Forderung, einen „Deut-

149 IfZ ED 145/45, Neue Offensive im Kalten Krieg, Aufzeichnung Sattlers vom 28. 2. 1956 über das Treffen der Kulturreferenten in Bonn.

150 Vgl. hierzu Manfred Regnery, Die Diskussion über die deutsche auswärtige Kulturpolitik zwischen 1957 bis 1963 unter besonderer Berücksichtigung der Deutschen UnescoKommission, Diss. phil. Freiburg i.Br. 1973.

151 „Die Zone arbeitet mit fast unbegrenzten Mitteln“, schrieb Karl Korn am 25. 3. 1959 in der Frankfurter Allgemeinen Zeitung, in welcher er unter dem Titel „Kurswechsel in der deutschen Kulturpolitik zum Ausland“ über die anstehende Ernennung Sattlers zum Leiter der Kulturabteilung und die damit zu erwartenden Neuerungen berichtete.

152 Vgl. Gerstenmaiers Ansprache über „Deutsche Kulturpolitik im Ausland“ auf der Jahrestagung des If A im November 1958, abgedruckt in: Mitteilungen. Institut für Auslandsbeziehungen, 8 (1958), S. 273-278. 
schen Kulturrat" nach Muster des British Council als staatsferne zentrale Koordinationsstelle zu schaffen.

Die Kulturabteilung des Auswärtigen Amts, auch dies eine Tradition aus der Zeit vor 1945, führte seit ihrer Wiedergründung ein ziemliches Schattendasein innerhalb des Amtes, wie die Klagen Salats und seiner Nachfolger während der ganzen fünfziger Jahre über zu wenig Personal zeigten. Die traditionelle Geringschätzung auswärtiger Kulturpolitik als Mittel der Diplomatie auch im neuen Amt zeigte sich u.a. an den ersten Leitern der Kulturabteilung: Bezeichnenderweise blieb Salat von 1951 bis 1954 kommissarisch mit der Führung der Kulturabteilung betraut, ohne daß man sich entschloß, einen Abteilungsleiter zu ernennen. Noch signifikanter für den Status der Kulturabteilung in den fünfziger Jahren als Karriereabstellgleis und als Nebenaspekt der Diplomatie, dem nicht allzuviel Beachtung geschenkt wurde, war der Fall Heinz Trützschler von Falkensteins, der sie von 1955 bis 1959 leitete. Er hatte nicht nur im Kriege die „Weißbücher" des Auswärtigen Amts zur Rechtfertigung der NS-Aggressionspolitik mitverfaßt, was an sich schon nicht gerade die ideale Empfehlung war, um die Kulturabteilung des Außenministeriums eines demokratischen Staatswesens zu leiten. Der Untersuchungsausschuß Nr. 47 des Bundestages, der im Herbst 1951 gegründet worden war, um zu klären, in welchem Maße das neue Auswärtige Amt von alten Parteigenossen durchsetzt sei, hatte Trützschler 1952 als vorläufig nicht beförderungswürdig und für den Auslandsdienst ungeeignet eingestuft. ${ }^{153}$ Erst die Ernennung Sattlers, eines gestandenen Kulturpolitikers, der bereits von 1947 bis 1950 Staatssekretär für die Schönen Künste in Bayern gewesen war, zum Leiter der Kulturabteilung schien Abhilfe zu schaffen. So wurde die Kulturabteilung nun allein schon dadurch äußerlich aufgewertet, daß ihr Leiter erstmals den Rang eines Ministerialdirektors erhielt. Trotz mehr Geld, mehr Personal und einer höheren Dotierung des Abteilungsleiterpostens erkannte Sattler freilich nach siebenjähriger Tätigkeit an der Spitze der Abteilung 6, daß die Kulturabteilung und damit die auswärtige Kulturpolitik selbst unter seiner Ägide nicht wesentlich mehr Gewicht innerhalb des Amts erhalten hatte als zuvor. ${ }^{154}$

Eine Neuerung Sattlers, die Ende 1960 realisiert wurde, war die Einrichtung eines das Amt in Fragen der auswärtigen Kulturpolitik beratenden Kulturbeirates. Er war sozusagen die „kleine Lösung“, nachdem die "große Lösung“ eines „Deutschen Kulturrates" nach dem Muster des British Council wegen der föderativen Ordnung der Bundesrepublik - die Kultusministerkonferenz hatte sich Anfang Februar 1959 gegen einen solchen ausgesprochen -, dem Beharrungsvermögen der bereits etablierten Mittlerorganisationen und der Angst, damit zunächst wieder nur eine weitere Bürokratie zu schaffen, nicht realisierbar gewesen war. Dies war bereits vor der Arbeitsaufnahme Sattlers in Bonn deutlich geworden. ${ }^{155}$

153 Döscher, Verschworene Gesellschaft, S. $231 \mathrm{f}$.

154 IfZ, ED 145/58, Bilanz 1959-1966: Sieben Jahre Kulturabteilung des Auswärtigen Amts, Aufzeichnung Sattlers vom 16. 4. 1966.

155 Schon die Frankfurter Allgemeine Zeitung berichtete am 25. 3. 1959, daß das Auswärtige Amt gegen einen „German Council“ sei und statt dessen einen Kulturbeirat erhalten 
Mit dem Vorschlag Sattlers, die Kulturinstitute unter einem einheitlichen Dach zu vereinen, für den er im vorhinein das Plazet von Brentanos erhalten hatte, ${ }^{156}$ griff Sattler die zuvor geäußerte Kritik an der Zersplitterung der deutschen auswärtigen Kulturpolitik in einem weiteren Aspekt konstruktiv auf, indem er zumindest in einem Teilbereich der auswärtigen Kulturpolitik eine Flurbereinigung durchführte, die ihm und Salat schon 1957 als notwendig erschienen war. ${ }^{157}$

Sattlers Initiative hinsichtlich der Kulturinstitute zielte auf einen besonders krassen Mißstand: Ende der fünfziger Jahre gab es nicht weniger als drei Formen der Trägerschaft für die deutschen Kulturstützpunkte im Ausland. Neben den 18 Auslandsdozenturen des Goethe-Instituts, die sich in Anlehnung an die früheren Lektorate der Akademie offiziell ausschließlich mit Sprachunterricht befaßten, gab es 1959 insgesamt 65 deutsche Kulturinstitute im Ausland, die von deutschausländischen Kulturgesellschaften betrieben wurden. Diese waren meist schon Anfang der fünfziger Jahre aus lokalen Initiativen vor allem in den traditionell deutschfreundlichen Ländern Südamerikas hervorgegangen und folglich hier überproportional stark vertreten. Daneben gab es noch 35 bundeseigene Kulturinstitute, die direkt dem Auswärtigen Amt unterstanden, sich allerdings wiederum in drei Kategorien unterteilten: In den als besonders wichtig angesehenen Metropolen Madrid, Rom, Lissabon, London, Stockholm, Oslo, Helsinki, Ankara, Kairo, Neu Delhi und New York waren zwischen 1955 und 1959 sukzessive repräsentative Einrichtungen eröffnet worden mit vom Auswärtigen Amt selbst ausgewähltem und entsandtem Personal, in der Regel ein Direktor und ein bis zwei Bibliothekskräfte. In der überwiegenden Zahl der Fälle wurden die bundeseigenen Institute, die eher Informationsbibliotheken als Veranstaltungsorten glichen, allerdings nebenamtlich von den Goethe-Dozenten oder den DAAD-Lektoren vor Ort geleitet, oder sie reduzierten sich auf reine, nur zeitweilig geöffnete Leseräume, die von den deutschen Auslandsvertretungen mitbetreut wurden.

Die Tatsache, daß ausgerechnet der Bund selbst die Kulturinstitute in den wichtigsten Hauptstädten betrieb, vergleichbar mit den DWI im Kriege, die Einrichtungen des Auswärtigen Amts gewesen waren, mutete um so befremdlicher an, als die Diplomaten nach 1945 eigentlich den Eindruck einer staatlich straff gelenkten auswärtigen Kulturpolitik unbedingt vermeiden wollten. Daß das Betreiben von Kulturinstituten durch das Auswärtige Amt und dessen Personalpolitik manch seltsame Blüte trieb, zeigt das Beispiel der im Januar 1958 in London eröffneten Einrichtung, welches, im noblen South Kensington am Hyde Park gelegen, der bislang teuerste Stützpunkt war. So wandte sich der erste Leiter, Donald Hirsch, im März 1959 an den Bundesaußenminister persönlich, mit dem er offenbar befreundet war - die Anrede in seinem Brief lautete immerhin „Lieber Heini!“ -, um Instruktionen für die Kulturarbeit zu erbitten, da er bislang keine klaren Weisun-

werde. Im Auswärtigen Amt selbst hatte sich u. a. der ehemalige Leiter der Kulturabteilung von Twardowski gegen einen „German Council“ ausgesprochen.

156 IfZ ED 145/45, Protokoll der Unterredung zwischen Brentano und Sattler vom 21. 12. 1958.

157 Ebenda, Aufzeichnung über ein Gespräch Sattlers, Salats und Steltzers in Rom am 16. 2. 1957. 
gen von anderer Seite habe erhalten können, weder von der Kulturabteilung der Zentrale, noch von der Botschaft in London. ${ }^{158}$ Dieses Bemühen um Rückversicherung war verständlich, denn zwei Jahre zuvor hatte Staatssekretär Walter Hallstein im Bundestag kritisiert, daß das Bochumer Schauspielhaus in Paris ein Stück von Bertolt Brecht aufgeführt hatte. Brecht wie im übrigen auch Franz Wedekind, befand der höchste Beamte des Auswärtigen Amts damals, seien nicht geeignet, deutsche Kultur im Ausland zu repräsentieren. ${ }^{159}$ Bundeseigene Kulturinstitute konnten nicht nur eine Art Beamtenmentalität schaffen, welche die Eigeninitiative erstickte. Sie machten die Institutsarbeit natürlich auch für Einmischungen aus der Zentrale anfällig. So wurde die Londoner Einrichtung in der Kulturabteilung dafür kritisiert, daß sie im ersten Jahr ihrer Existenz die Mehrzahl der Veranstaltungen auf Englisch abgehalten habe, während lebensnahe Vorträge auf Deutsch zur aktuellen Kultur der Bundesrepublik gefehlt hätten. Hierunter verstand der Referent u.a.Themen wie „Sitten und Bräuche der einzelnen Bundesländer" oder „Deutsche Märchen im Wandel der Zeiten“ ${ }^{160}$ Bei der ersten Bundestagsdebatte zur auswärtigen Kulturpolitik der Bundesrepublik überhaupt im Juni 1960 kritisierte denn auch der Redner der SPD, Georg Kahn-Ackermann, die bisherige Arbeit der bundeseigenen Kulturinstitute. Diese stehe, wie man auch jüngst in der Presse habe lesen können, mehr oder weniger unter dem Motto „edel, aber verstaubt“, es herrsche eine „kulturelle Kaffeekränzchenatmosphäre“. Ursache hierfür sei nicht zuletzt die Angst der Leiter der Institute vor Maßregelungen der Zentrale, die offenbar auch auf dem Gebiet der auswärtigen Kulturpolitik der Devise „Keine Experimente" folge. Nicht zuletzt deshalb konzentriere man sich in den Instituten auf die Verbreitung unverfänglicher "klassischer" deutscher Kultur, während Themen zur deutschen Kultur und Politik nach 1914 kaum anzutreffen seien: Der Leiter des Instituts in Rom beispielsweise habe seine ganze Energie darauf verwendet, eine Bach-Gesellschaft ins Leben zu rufen. ${ }^{161}$

Direkt dem Amt unterstehende Kulturinstitute erwiesen sich auch insofern als ungeeignet, als die Kulturabteilung in Bonn schlichtweg nicht das Personal hatte, die Institute in ihrer inhaltlichen Arbeit wie auch administrativ angemessen zu betreuen, ganz abgesehen davon, daß das traditionelle Rotationsprinzip im Auswärtigen Amt eine kontinuierliche inhaltliche Zusammenarbeit ohnehin unmöglich machte. Sattler wußte 1959, daß er zwar auf eine erhebliche Erhöhung der Kulturund Schulfonds des Auswärtigen Amts in den nächsten Jahren hoffen konnte, eine entsprechende Aufstockung des Beamtenstabs der Kulturabteilung hingegen wegen der damit verbundenen langfristigen finanziellen und personalpolitischen Implikationen für das Amt nicht sehr aussichtreich sein würde. ${ }^{162}$ Aus diesen Gründen wurde die sich 1959 abzeichnende Überantwortung der Kulturinstitute an das

158 PA B1/100, Brief Hirschs an von Brentano, 18. 3. 1959.

159 Verhandlungen des Deutschen Bundestages. 2. Wahlperiode, Sitzung vom 4. 4. 1957, S. $11391 \mathrm{f}$.

160 PA B96/569, Aufzeichnung betr. Tätigkeitsbericht des Kulturinstituts in London für 1958, 12. 5. 1959.

161 Verhandlungen des Deutschen Bundestages. 3. Wahlperiode, Sitzung vom 23.6. 1960, S. $6872 \mathrm{f}$.

162 Stoll, Kulturpolitik als Beruf, S. 369. 
Münchener Institut in der Kulturabteilung grundsätzlich befürwortet, vorausgesetzt, ihr werde eine Mitsprache bei wichtigen Entscheidungen eingeräumt, in erster Linie bei der Ernennung der Leiter der bedeutendsten Institute, dem Umfang der den einzelnen Instituten zustehenden Mittel und den auszuarbeitenden inhaltlichen Richtlinien. ${ }^{163}$

Für eine Zusammenfassung aller Institute ausgerechnet unter dem Dach des Münchener Vereins sprachen noch andere Gründe: Die Kulturinstitute, die nicht direkt vom Goethe-Institut gegründet worden waren, hielten teilweise auch Deutschkurse ab, für die nicht selten speziell dafür entsandte Goethe-Dozenten eingesetzt oder von der örtlichen Goethe-Dozentur abgestellt wurden. Dies hatte in München schon zu Unmut geführt, da der Name des Vereins, nach dessen Muster der Deutschunterricht auch in diesen Einrichtungen erfolgte, nach außen nicht in Erscheinung trat. Magnus hatte schließlich sogar mit dem Ende der $\mathrm{Zu}-$ sammenarbeit zwischen dem Goethe-Institut und den bundeseigenen Einrichtungen im Ausland gedroht. ${ }^{164}$ In der Kulturabteilung wiederum hatte man schon 1957 mit Blick auf die besonders zugkräftige Goethe-Dozentur in Athen ${ }^{165}$ erkannt, daß einige Auslandsstützpunkte des Münchner Vereins die Aufgabe eines Kulturinstituts durchaus erfüllten und daher vom Auswärtigen Amt finanziell besonders gefördert werden sollten, da sie die Errichtung eines bundeseigenen Kulturinstituts an gleicher Stelle überflüssig machten. ${ }^{166}$ Schließlich war das GoetheInstitut am Ende des Jahrzehnts ohnehin zum überwiegenden Teil von Subventionen aus Bonn abhängig geworden, so daß eine einheitliche Zusammenfassung aller Kulturinstitute unter dem Dach der Münchener Einrichtung nur eine konsequente Fortentwicklung der bestehenden finanziellen Kooperation sein würde. Es waren aus Sicht des Auswärtigen Amts vor allem organisatorische Erwägungen, die eine Übertragung der Kulturinstitute auf den Münchener Verein geraten erschienen ließen, und nicht so sehr die Erwartung, daß somit auch eine thematisch zeitgemäßere Kulturwerbung im Ausland möglich sein würde. Für Sattler spielten noch zwei weitere Erwägungen eine Rolle, die gleichsam in einem negativen Auswahlverfahren letztlich nur das Goethe-Institut in München als organisatorisches Dach übrig ließen. Die zukünftig wichtigste Mittlerorganisation sollte auf jeden

163 PA B96/569, Aufzeichnung betr. die Übernahme der deutschen Kulturinstitute im Ausland durch das Goethe-Institut, 14.10. 1959.

164 BAK B307/42, Protokoll der Sitzung des Vorstands, 27. 6. 1959; PA B96/569, Aufzeichnung betr. bundeseigene Kulturinstitute, an denen Dozenten des Goethe-Instituts tätig sind, 1. 7. 1959.

165 Die Athener Zweigstelle war und ist wegen des großen Werts, der in Griechenland traditionellerweise auf die Beherrschung von Fremdsprachen gelegt wird, seit ihrer Gründung das größte Goethe-Institut. Im Jahre 1999 wurden hier beispielsweise 27507 Unterrichtseinheiten in DaF gegeben im Vergleich zu 14604 in Paris, 11431 in Moskau, 10995 in Warschau, 8762 in London und 8718 in Rom. Mehr als die Hälfte aller Prüfungen in DaF in sämtlichen Goethe-Instituten der Welt wurden im Jahre 1999 in den Instituten in Athen und Thessaloniki abgelegt, nämlich 18342 von weltweit 35882 . Vgl. Goethe-Institut (Hrsg.), Jahrbuch 1999/2000, München 2000, passim.

166 BAK B307/25, Aufzeichnung betr. die Tagung des Vorstandes und Verwaltungsrates des Goethe-Instituts vom 24. 5. 1957; Aufzeichnung des Leiters der Kulturabteilung von Trützschler vom 5.6. 1957. 
Fall in einer deutschen Stadt angesiedelt sein, die eine gewisse Ausstrahlungskraft auf das Ausland habe. Dies schloß in den Augen des Müncheners Sattler die in dem als zu provinziell erachteten Bonn angesiedelten Institutionen DAAD, Inter Nationes und Alexander-von-Humboldt-Stiftung aus, ebenso das IfA in Stuttgart. Zudem hatte Sattler gegen den dortigen Generalsekretär Thierfelder Vorbehalte: Dieser sei zu deutsch-national eingestellt und als Persönlichkeit ungeeignet, um ihm die Leitung einer derart wichtigen Einrichtung anzuvertrauen. ${ }^{167}$ In München wurde Sattlers Initiative naturgemäß begrüßt, da sich aus ihr ganz neue Entwicklungsperspektiven für den Münchener Verein ergaben.

Dieser neue Abschnitt in der Geschichte des Goethe-Instituts wurde zunächst recht formlos besiegelt. Sattler bat Magnus, ein entsprechendes Memorandum zu verfassen. In diesem auf den 5. September 1959 datierten Schriftstück legte Magnus folglich die Vorteile der Vereinigung der Kulturinstitute unter einem organisatorischen Dach dar. Hauptargument war, daß sich Sprach- und Kulturarbeit ohnehin nicht trennen ließen. So wie jede Sprachschule zumindest ihren fortgeschrittenen Hörern ein gewisses Kulturprogramm bieten müsse, würden erst regelmäßige Sprachkurse einem Kulturinstitut auch einen ausreichend großen Stamm von Interessenten für dessen andere Aktivitäten garantieren. Es sei ferner ungerecht und politisch unklug, daß das Goethe-Institut den bundeseigenen Kulturinstituten bei der Spracharbeit unter die Arme greife, aber nicht namentlich genannt werde, obwohl in manchen Ländern gerade gegen staatlich organisierte Sprachkurse stärkere Vorbehalte beständen als gegen solche, die von einem privaten Verein ausgerichtet würden. Schließlich könne ein Verein wie das Goethe-Institut die Verwaltung der Institute effektiver und kostengünstiger als eine Behörde bewerkstelligen. Die Kulturabteilung gab Magnus' Vorschlägen durch ein Schreiben Sattlers vom 16. November 1959 an das Goethe-Institut ihr Plazet. ${ }^{168}$

Im Frühjahr 1960 gingen die ersten bundeseigenen Institute in Tunis, Alexandria, Madras, Saigon und Singapur in die Obhut des Münchener Vereins über. Nach außen hin deutlich wurde diese Erweiterung des Wirkungsbereichs 1961 durch die Umbenennung des Münchener Vereins in "Goethe-Institut e.V. zur Pflege der deutschen Sprache und Kultur im Ausland“ und durch Gründung einer Programmabteilung zum 1. Januar 1962. Ein förmlicher, erster Vertrag zwischen Goethe-Institut und Auswärtigem Amt über die Modalitäten der künftigen $\mathrm{Zu}$ sammenarbeit wurde allerdings erst am 3. Juli 1963 unterzeichnet. Dennoch, bereits seit Sommer 1959 waren die Weichen in Bonn und München dafür gestellt, daß fortan der Begriff „Goethe-Institut" Synonym für ein deutsches Kulturinstitut im Ausland sein würde.

167 Stoll, Kulturpolitik als Beruf, S. 370.

168 BAK B307/159. 